1 Title

2 Potential of indicators to unveil the hidden side of cropping system classification: differences

3 and similarities in cropping practices between conventional, no-till and organic systems

4

5 Authors

6 Lucie Büchi ${ }^{1,2, *}$, Florent Georges ${ }^{1}$, Florian Walder $^{3}$, Samiran Banerjee ${ }^{3}$, Thomas Keller ${ }^{3,4}$,

7 Johan Six $^{5}$, Marcel van der Heijden ${ }^{3}$, Raphaël Charles ${ }^{1,6}$

8

\title{
9 Affiliation
}

10 Plant Production Systems, Agroscope, Nyon, Switzerland

11 2Natural Resources Institute, University of Greenwich, Chatham, United Kingdom

$12{ }^{3}$ Agroecology and Environment, Agroscope, Zurich, Switzerland

$13{ }^{4}$ Soil and Environment, Swedish University of Agricultural Sciences, Uppsala, Sweden

$14{ }^{5}$ Environmental Systems Sciences, Swiss Federal Institute of Technology, ETH Zurich,

15 Zurich, Switzerland

$16{ }^{6}$ Research Institute of Organic Agriculture FiBL, Lausanne, Switzerland

17

18 *Corresponding author: L.A.Buchi@greenwich.ac.uk 


\section{Abstract}

23 To compare different cropping systems, it is crucial to describe explicitly the associated cropping practices. A set of 31 indicators, and six composite indexes, addressing farm structure, crop diversification, soil disturbance, organic matter inputs, nitrogen fertilisation, crop protection, and yield was used to describe 59 winter wheat fields belonging to conventional, no-till and organic systems, in Switzerland. The aim of this study was to investigate the complementarity and redundancy of the indicators and their potential to characterise these cropping systems. In general, weak correlations were observed between the studied indicators, showing the importance of using a set of indicators to fully characterise cropping practices. The complex indicators were often correlated with simpler ones, but it cannot be excluded that they can prove to be more useful in different contexts. Retaining a combination of simple and complex indicators to obtain a broad picture of cropping practices

34 is thus recommended. The indicators highlighted differences but also similarities between the three systems. For example, the input of organic matter and crop rotation diversification were similar between the three systems. In contrast, total nitrogen fertilisation (lower for organic systems) and soil disturbance (lower for no-till systems) were different. A high within-system variability was observed for some indicators, suggesting that using quantitative indicators rather than simple classifications based on a general description of the systems allows a better characterisation of these systems. Overall, the use of indicators has the potential to improve our understanding of the influence of cropping practices on the soil and environment.

\section{Keywords}

44 field level indicators, composite indexes, crop diversification, organic matter inputs, soil 45 disturbance intensity, on-farm study 


\section{Introduction}

47 Agriculture is characterised by a wide range of soil management and cropping practices, such as choice of cultivated crop and cultivar, crop rotation, tillage intensity and implements, nutrient management, crop protection and irrigation. As alternatives to what can be called 'conventional' cropping practices, different cropping systems have been developed, especially to reduce the impact of agriculture on the environment. Among others, organic farming and no-till agriculture are alternative systems which are increasingly adopted. Organic farming is principally based on the exclusive utilisation of organic fertilisers and treatments: synthetic substances are prohibited but soil tillage and mechanical weeding is allowed (Reganold and Wachter, 2016; Migliorini and Wezel, 2017). No-till farming implies the absence of any tillage interventions prior to seeding and should ensure at least $30 \%$ soil cover throughout the year (Soane et al., 2012). No-till systems could fulfil the principles of conservation agriculture if they insure sufficient soil cover (by residues or crops) and a diversified crop sequence (FAO, 2018).

Many studies have aimed at comparing these systems to assess if yield can be maintained compared to conventional systems. Based on a meta-analysis, it has been shown that no-till alone tends to reduce yield by about $10 \%$, but this decrease can be mitigated when no-till is associated with crop residue retention and improved crop rotation (Pittelkow et al., 2015a). In organic farming, a yield decline of about $20 \%$ compared to conventional systems is typically observed (Mäder et al., 2002; de Ponti et al., 2012; Seufert et al., 2012; Ponisio et al., 2015; Seufert and Ramankutty, 2017). Moreover, a recent meta-analysis has shown that temporal yield stability of conventional fields was higher than that of organic fields (Knapp and van der Heijden, 2018). However, precautions must be taken when comparing these systems as observed differences could be induced by confounding factors (e.g. soil or climatic factors), or fundamental differences in the system design such as differences in crop rotation (Kirchmann et al., 2016). Most often, systems are compared by 'labels' without specifying to 
which extent these systems actually differ in terms of cropping practices (Armengot et al.,

73 2011; Therond et al., 2017). However, information on cropping practices is crucial when it

74 comes to understand and explain the observed effects on yield, plant performance or soil

75 properties. The amount of organic amendments, the intensity of tillage, the extent of fertiliser 76 inputs, the number and amount of pesticides used, and the crop diversity may vary drastically 77 within a given type of cropping system.

78 Indicators of agricultural practices can be used to achieve such a description. Many sets of indicators aiming at describing farming and cropping systems exist, from simple ones to complex multi-dimensional assessment tools (Bockstaller et al., 1997; Bockstaller et al., 2008; Pelzer et al., 2012). The choice of the indicators depends on the objective of the study. In many studies, indicators are chosen to characterise the sustainability of the system or the intensity of management and practices (i.e. land-use intensity LUI) (e.g. Bechini and Castoldi, 2009; Geiger et al., 2010; Gaudino et al., 2014; Smith et al., 2017). These primary indicators can then be combined to obtain secondary composite indexes (Nardo et al., 2005; Castoldi and Bechini, 2010; Blüthgen et al., 2012) to reduce the dimensionality of the data and allow more straightforward interpretations of the results. A drawback of this is obviously the loss of information and the potential concealing of trade-offs between practices. Different methods to build these composite indexes exists (Nardo et al., 2005), the two most common being additive aggregation of indicators after normalisation (e.g. Herzog et al., 2006; Blüthgen et al., 2012) and the use of multivariate analyses such as PCA (e.g. Armengot et al., 2011; Nkurunziza et al., 2017). However, the collection of the data needed to implement such indicators is a daunting task and thus simple and reliable indicators, based on data that is reasonably easy to obtain, are required.

Here, we present results from an on-farm study conducted in Switzerland in 2016-2017, on winter wheat fields belonging to three cropping systems, conventional, no-till and organic. A survey was conducted to gather information about management and cropping practices at field 
and farm scale. Based on these data, 31 indicators of different complexity levels were computed to cover the main characteristics of the cropping systems. For three thematic categories of indicators, composite indexes were computed using the multivariate and additive 101 aggregation methods.

102 The aims of this study were a) to assess the complementarity and redundancy of the 31 chosen 103 indicators and of the composite indexes and b) to evaluate the potential of these indicators to 104 characterise the three cropping systems.

105 comply to their specific cropping system for more than five years. All conventional and no-till

117 farms followed the 'Proof of Ecological Performance' guidelines from the Swiss Federal

118 Office for Agriculture, which include a balanced nutrient budget, diversified crop distribution

119 (at least four different main crops per year), proper soil protection, targeted selection and use of pesticide treatments and biodiversity promoting surfaces (FOAG, 2018a). Organic farms

121 followed the guidelines of Bio Suisse, which is the federation of Swiss organic farmers.

122 Prerequisites were that the fields should have been seeded with winter wheat in autumn 2015

123 and be larger than 1 ha. Winter wheat fields were targeted as this is the most frequent crop in 
124 Switzerland, representing more than $20 \%$ of the arable surface (FSO, 2016). The most

125 common crop rotation in the type of farms studied here has a cereal crop every two years; and

126 the most cultivated crops outside from cereals are maize (silage or grain), rapeseed and sugar

127 beet. Fields belonging to Cambisols with minimum $10 \%$ to maximum $40 \%$ of clay were

128 targeted (Figure S2).

129 In order to check for a potential sampling effect on differences between cropping systems,

130 information about six pedoclimatic variables (clay and silt content $(0-20 \mathrm{~cm})$, altitude, mean

131 annual temperature and precipitation) were also gathered. Temperature and precipitation data

132 were taking from the closest available weather station for each field.

\section{$134 \quad 2.2$ Cropping practice indicators}

135 Cropping practices were characterised according to 31 indicators, grouped into six thematic

136 categories, as described below and summarised in Table 1. The data needed to compute these

137 indicators were gathered from the farmers through a survey. Most questions were closed

138 questions, i.e. several options of pre-defined answers were given. Information about the

139 general farm structure and the specific cropping practices of the selected winter wheat field

140 were collected (Table S2). Two types of time periods were used to collect data on cropping

141 practices of the winter wheat field: detailed information on all cropping practices including

142 dates of treatment for the crop cultivation year (winter wheat 2015-2016, period going from

143 the harvest of the previous crop to the harvest of the winter wheat), and information on the

144 five-year crop rotation, gathered for the wheat year and the four preceding years (2012-2016)

145 (Table 1 and S2). The used indicators were chosen among published indicators or standard

146 farm or field descriptors. These indicators differed in their complexity, i.e. the amount of

147 information needed to compute them. 
148 Because survey results could not be obtained from one of the farms, all analyses involving

149 cropping practice indicators were performed on 59 values (19 for the 'conventional' group, 20

150 for the 'no-till' group and 20 for the 'organic' group).

\section{$152 \quad$ Farm structure}

153 For this category, the indicators concerned the farm scale, whereas the five other categories

154 refer to field scale. Farm structure was described by three indicators: utilised agricultural area, 155 including fallow surface ('UAA', in ha), annual working unit ('AWU', full time equivalent, a

156 value of 1 corresponds to 1 person working full time on the farm the whole year) and

157 livestock unit per hectare of UAA ('LSU', a value of 1 corresponds to 1 dairy cow per hectare)

158 (Table 1). In addition, the diversity at the farm level in the year 2016 including crops, leys and 159 fallows, was assessed ('farmDiv').

\section{Crop diversification}

162 Crop diversification was addressed using five indicators. The number of years in ley

163 ('nbLeys'), the number of legumes ('nbLeg') and cover crops ('nbCC') occurrence during the

164 five-year crop rotation 2012-2016 was quantified. Legumes species count included main

165 crops as well as cover crops. The number of cover crops was also compared to the potential

166 maximum number of cover crops that could have been cultivated given the crop rotation. It

167 was assumed that a cover crop could be cultivated whenever there were more than eight

168 weeks between the harvest of the previous crop and the seeding of the new one, based on

169 standard harvest and seeding dates. Crop diversity ('cropDiv') was then computed as the

170 number of different crops (main and cover) cultivated during the five years. A crop rotation

171 diversification index ('rDiversification') was derived following the Indigo method

172 (Bockstaller and Girardin, 2000), adapted here for a five-year duration. This indicator takes 
173 into account crop rotation diversity, identity of the preceding crop and the time to the previous

174 wheat crop.

175

\section{Soil disturbance and protection}

177 A total of seven indicators were selected to assess soil disturbance and protection. Field traffic

178 ('traffic') was the number of interventions on the field, all type of interventions included, 179 during the wheat cultivation period 2015-2016. The number of tillage ('nbTill') and 180 mechanical weeding ('nbWeed') operations during that period were also used as indicators.

181 Then, the mean number of tillage and weeding interventions over the five-year crop rotation 182 ('nbTW') was computed. Fifth, a simple soil protection index ('soilP') was derived from the 183 IDEA method (Zahm et al., 2008), based only on the type of soil tillage adopted in the last 184 five years. It consisted in attributing a weight to each type of tillage (plough $=0.5$, reduced 185 tillage $=3$, no-till $=5$ ) for each year of the crop rotation, and then averaging it. Soil tillage 186 intensity rating ('stir') was computed for the wheat cultivation period, based on the 187 disturbance induced by each tillage implement ('Soil Tillage Intensity Rating STIR' method 188 from the RUSLE2 framework, USDA, 2012). In this method, a tillage intensity coefficient is 189 attributed to each type of tillage implement as a function of tillage depth, area, speed and 190 intensity. A list of such coefficients for different machines and interventions are available 191 from the RUSLE2 method. The total tillage intensity was computed as the sum of these 192 coefficients for all the interventions done during seedbed preparation and weeding. Last, the 193 mean soil cover ('sCover') provided by crop residues or cover crops during the pre-sowing 194 period (from the harvest of the preceding crop to the seeding of the winter wheat in 2015) was 195 assessed using the soil cover indicator described by Büchi et al. (2016). It is based on standard 196 values of soil cover by crop residues after harvest and incorporation rate by tillage 197 implements. A minimal threshold value of 30\% cover is generally seen as providing proper 198 soil protection (Armand et al., 2009; Lilley and Moore, 2009; FAO, 2018). 
200 Organic matter inputs and nitrogen fertilisation

201 The topic of organic matter was represented by five indicators. First, crop residue

202 management ('resExp') was evaluated by the frequency of crop residue exportation during the 203 five-year crop rotation. Second, the number of organic amendment inputs ('nbOrg') over the 204 crop rotation was counted. Third, an estimation of the corresponding quantity of stable 205 organic matter input ('qOrg', $\mathrm{kg} \mathrm{OM} / \mathrm{ha}$ ) was computed on a dry matter basis, using isohumic 206 treatments ('nbFung') and total number of treatments ('nbTreat', i.e. herbicide, fungicide, molluscicide, insecticide, growth regulator) were computed. When several products were 224 applied together, each product counted as a separated treatment. Then, an herbicide ('rHerb') 
and total ('rTreat') relative treatment frequency index was computed, based on the index

226 developed in France (Hossard et al., 2017). This index is computed as the sum of the ratio of applied treatment dose over recommended dose, over all treatment applications. The recommended dose of each product was extracted from the website of the Swiss Federal Office for Agriculture (FOAG, 2018b). When a range of doses was indicated, the mean value 230 was used.

$\underline{\text { Yield }}$

Wheat yield in 2016 as recorded by the farmer was considered ('yield', t/ha), as well as 234 relative yield ('relY') over the five-year crop rotation. The farmers generally estimated yield 235 as the ratio between the total amount of wheat grain sold and the cultivation surface. Relative 236 yield was computed as the mean ratio of effective yield (as recorded by the farmers) over 237 Swiss reference yield of the different crops (Sinaj and Richner, 2017). Each crop has a unique 238 reference yield value for Switzerland, determined for conventional practices.

\subsection{Composite intensity indexes}

241 Two composite indexes were computed based on subsets of indicators to characterise the 242 intensity of cropping practices, using two different methods.

\section{Multivariate approach index I}

244 The first method consisted in using as composite index, thereafter called $\mathrm{I}_{\mathrm{PCA}}$, the first 245 principal component of a PCA performed on the selected indicators, after standardisation of 246 the variables (e.g. Armengot et al., 2011).

\section{Additive aggregation index $\mathrm{I}_{\mathrm{add}}$}

248 In the second method, the composite index, thereafter called $\mathrm{I}_{\text {add }}$, is based on an additive 249 combination of the indicators after normalisation, as in Herzog et al. (2006). For each 
250 indicator, normalisation was done following Herzog et al. (2006), to scale the values between

2510 and 1, 1 representing the highest and more intense value:

$252 \mathrm{nI}=\left(\mathrm{y}_{\mathrm{i}}-\mathrm{y}_{\min }\right) /\left(\mathrm{y}_{\max }-\mathrm{y}_{\min }\right)$

253 where $\mathrm{nI}$ is the normalised indicator, $\mathrm{y}_{\mathrm{i}}$ the individual values, $\mathrm{y}_{\min }$ the minimal value and $\mathrm{y}_{\max }$ 254 the maximal value. In order to reduce the influence of outliers, we followed the 255 recommendation of Nardo et al. (2005) and replaced the $y_{i}$ values higher than the $97.5 \%$ or 256 lower than the $2.5 \%$ percentiles by these threshold values. The composite index $\mathrm{I}_{\text {add }}$ was then 257 obtained by averaging the normalised indicators, with similar weight for all indicators.

$258 \quad \mathrm{I}_{\mathrm{add}}=\frac{\sum_{i=1}^{n} n I}{n}$

259 where $\mathrm{n}$ is the number of indicators to aggregate.

260 In contrast to the PCA method, which is 'neutral', here a decision about the direction of each 261 indicator must be done prior to the aggregation. 'Direction' is meant as a statement about 262 which values (high or low, or sometimes even intermediate) represent the most intense 263 practice. While this could be relatively straightforward for some indicators, as for example for 264 the number of pesticide treatments, it could be more debatable for some others, for example 265 for the input of organic matter. The direction of the intensity gradient could also depend on 266 the intended use of the index: an index to interpret environmental impact could be built 267 differently from and index to interpret soil organic carbon stocks. Thus, in some cases, 268 individual indicators need to be reversed to have all indicators pointing in the same direction. 269 This was done here by using $1-n \mathrm{nI}$ rather than $\mathrm{nI}$ in the final aggregation (Table 2).

271 These two composite indexes were computed for the three categories Crop diversification, 272 Soil disturbance and protection and Organic matter inputs and nitrogen fertilisation. No 273 composite index was computed for the Crop protection category as the indicators total number 
274 of treatments 'nbTreat' and total treatment frequency index 'rTreat' already represented an

275 aggregated information about different pesticide treatment applications.

276 For each category, the indicators included in the composite indexes were chosen in order to 277 exclude highly correlated indicators (Kendall's rank correlation $\tau>0.7$, see section 2.4 ) and 278 indicators of high complexity (requiring a lot of information to be computed), in order to 279 study if composite indexes based on simple indicators provide the same type of information as 280 complex indicators. The indexes obtained with each method were compared with each other 281 as well as with the more complex indicators in the same category, if available (Table 2). The 282 indicators used to compute the composite indexes, and their direction for the computation of 283 the additive aggregation index $\mathrm{I}_{\text {add }}$, are shown in Table 2.

\subsection{Data analyses}

Differences between the three cropping systems for pedoclimatic variables, primary cropping 287

294 farm and field indicators.

295 The results obtained for the farm structure indicators were compared to Eurostat data 296 (Eurostat, 2018) to situate the studied farms relative to other European countries. Data from 297 the 2010 Eurostat survey were used as they also included data from Switzerland. The 298 proportion of area under organic farming (\%UAA) in 2016 was also shown for comparison 299 purpose. 
300 All statistical analyses were performed using R 3.5.1 (R Core Team, 2018).

301

302 3. Results

\section{3.1 Field characteristics}

304 Of the 60 fields, the most frequent soil texture (ISSS texture triangle) was clay loam (31 305 fields), followed by loam (13), light clay (12), silty clay loam (2) and silty clay (1) (Figure 306 S2). The proportions of these textures did not differ between cropping systems (Chi-square 307 test, $p=0.646)$. Altitude ranged between $356 \mathrm{~m}$ and $754 \mathrm{~m}$ above sea level, mean annual 308 temperature (2015-2016) between $9.3^{\circ} \mathrm{C}$ and $11.7^{\circ} \mathrm{C}$, and mean annual precipitation (2015309 2016) between $680 \mathrm{~mm}$ and $1322 \mathrm{~mm}$. However, the three cropping systems did not show 310 significant differences for these variables ( $p>0.05$, based on analyses of variance). Thus, no 311 confounding effect of the pedoclimatic variables could be seen here.

\subsection{Complementarity versus redundancy of indicators of different complexity}

\section{$314 \quad \underline{\text { Farm structure }}$}

315 At the farm level, the indicators were generally not correlated, except for utilised agricultural 316 area UAA and working units AWU which showed a slight positive correlation (Kendall's rank 317 correlation $\tau=0.50, \mathrm{p}<0.001$ ), also visible in the PCA (Figure 1A). Farm scale diversity 318 farmDiv was also significantly positively correlated with UAA but the correlation was weak $319(\tau=0.26, \mathrm{p}<0.007)$

\section{Crop diversification}

322 Overall, the Crop diversification indicators showed some complementarity and were not

323 highly correlated with each other (Figure 1B). Compared to the simpler indicators, the

324 complex crop rotation diversification indicator rDiversification takes into account different

325 type of information (i.e. crop rotation diversity, identity of the preceding crop and the time to 
the previous wheat crop). It was slightly correlated with crop diversity cropDiv (Kendall's rank correlation $\tau=0.30, p<0.004$ ), but not with all the other indicators presented here (Figure 1B). Crop diversity was positively correlated with the number of cover crops nbCC $(\tau=0.60$, $\mathrm{p}<0.001)$ and negatively correlated with the number of leys nbLeys $(\tau=-0.53, \mathrm{p}<0.001)$. The number of leys was also correlated with nbCC $(\tau=-0.54, \mathrm{p}<0.001)$ and the number of legumes $331 \operatorname{nbLeg}(\tau=-0.44, \mathrm{p}<0.001)$.

332 The composite indexes were computed using nbCC, nbLeys, nbLeg and cropDiv. The index 333 based on the PCA $I_{\mathrm{PCA}}$ was positively correlated with nbLeys and nbLeg but negatively with $334 \mathrm{nbCC}$ and cropDiv (Figure S3). In contrast, the index based on the additive aggregation $\mathrm{I}_{\text {add }}$ 335 was, by construction, positively correlated with the four indicators. These two composite 336 indexes $\mathrm{I}_{\mathrm{PCA}}$ and $\mathrm{I}_{\text {add }}$ were not correlated with each other, but $\mathrm{I}_{\text {add }}$ was weakly correlated with 337 the complex crop rotation diversification indicator $(\tau=0.21, \mathrm{p}=0.027)$.

\section{Soil disturbance and protection}

340 The indicators linked to soil disturbance and protection showed high redundancy, with almost

341 all indicators significantly correlated with each other (Figure 1C). In particular, the complex 342 soil tillage intensity indicator stir was correlated with all the others, with some correlations 343 higher than 0.6. For example, the simple soil protection indicator soilP, which relies only on

344 the general type of tillage (plough, minimum or no-till) applied each year, was correlated with 345 the stir indicator $(\tau=-0.47, \mathrm{p}<0.001)$, which integrated more specific information about crop 346 management. The other complex indicator linked to soil cover sCover was also correlated 347 with all the other except traffic. The sum of tillage and mechanical weeding interventions in 3482016 nbTW was highly correlated with the mean number of tillage nbTill and weeding

349 nbWeed interventions over the five-year crop rotation $(\tau=0.73, p<0.001)$, showing that, in this 350 study, most farmers were consistent through time in terms of interventions (i.e. tillage and 351 weed management). 
352 Given these high correlations between indicators, only four basic indicators were used to 353 compute the composite indexes (traffic, nbTill, nbWeed and soilP). The index based on the

354 PCA I $\mathrm{PCA}_{\text {was }}$ wositively correlated with traffic, nbTill and nbWeed but negatively with soilP

355 (Figure $\mathrm{S} 3$ ). A similar result was obtained for the index based on the additive aggregation $\mathrm{I}_{\text {add }}$.

356 These two composite indexes $\mathrm{I}_{\mathrm{PCA}}$ and $\mathrm{I}_{\mathrm{add}}$ were highly correlated with each other $(\tau=0.91$,

$357 \mathrm{p}<0.001)$, and with the complex indicators $\operatorname{stir}(\tau=0.68$ and $0.64, \mathrm{p}<0.001)$ and $\mathrm{sCover}(\tau=-$

$358 \quad 0.35$ and $-0.34, \mathrm{p}<0.001)$.

359

$\underline{\text { Organic matter inputs and nitrogen fertilisation }}$

361 Some significant correlations were observed between indicators linked to organic matter and

$362 \mathrm{~N}$ inputs (Figure 1D). The number of organic amendments nbOrg was not related with the 363 amount of organic matter provided $\mathrm{qOrg}(\tau=0.17, \mathrm{p}=0.124)$. The total amount of organic 364 matter input totOrg was highly correlated with $\mathrm{qOrg}(\tau=0.72, \mathrm{p}<0.001)$, as the input through 365 crop residues cropOrg was small compared to the total quantity. In turn, the organic matter 366 coming from crop residues cropOrg was correlated with the less complex crop residue 367 exportation indicator resExp $(\tau=-0.37, \mathrm{p}<0.001)$. Total nitrogen fertilisation tot $\mathrm{N}$ was highly 368 correlated $(\tau=0.72, \mathrm{p}<0.001)$ with mineral fertilisation $\operatorname{minN}$, as the amount provided by 369 organic fertilisation orgN was low. This category thus contained two indicators which were 370 computed as the sum of two others (totOrg $=\operatorname{cropOrg}+q$ Org and $\operatorname{tot} \mathrm{N}=\operatorname{minN}+\operatorname{orgN})$, and 371 these showed high correlations with one of their components, totOrg with qOrg and totN with $372 \operatorname{minN}$. They were thus not used to compute the composite indexes. Here, the index based on 373 the PCA $\mathrm{I}_{\mathrm{PCA}}$ was positively correlated with resExp, nbOrg and orgN, and negatively with 374 qOrg, cropOrg and minN (Figure S3). The index based on the additive aggregation $\mathrm{I}_{\text {add }}$ was 375 positively correlated with all indicators except cropOrg. These two composite indexes $\mathrm{I}_{\mathrm{PCA}}$ 376 and $\mathrm{I}_{\text {add }}$ were slightly correlated with each other $(\tau=0.25, \mathrm{p}=0.005)$, but not with totOrg. $\mathrm{I}_{\mathrm{PCA}}$, 377 but not $\mathrm{I}_{\mathrm{add}}$, was significantly correlated with totN $(\tau=-0.45, \mathrm{p}<0.001)$. 


\section{$\underline{\text { Crop protection }}$}

380 Crop protection indicators were highly correlated to each other (Figure 1E). The total number 381 of treatments nbTreat was correlated with its two main components, the number of herbicides $382 \operatorname{nbHerb}(\tau=0.72, \mathrm{p}<0.001)$ and of fungicides nbFung $(\tau=0.55, \mathrm{p}<0.001)$.

383 In this study, adding a level of complexity to the crop protection indicators, by passing from 384 the number of pesticide treatments to an integration of applied doses did not bring new 385 insights (Figure 1E). The number of herbicide treatments nbHerb was highly correlated to the spring.

\subsection{Potential of indicators to characterise cropping systems}

relative frequency index $\operatorname{rHerb}(\tau=0.90, \mathrm{p}<0.001)$, a similar result was observed for the total number of treatments nbTreat and its relative frequency index rTreat $(\tau=0.90, p<0.001)$.

\section{$\underline{\text { Yield }}$}

Overall, wheat grain yield in 2016 was positively correlated with the relative yield indicator obtained over the five-year crop rotation relY $(\tau=0.58, \mathrm{p}<0.001)$ (Figure $1 \mathrm{~F})$. However, the correlation coefficient for the no-till systems $(\tau=0.28$, non-significant, $p=0.08)$ was much lower than for the conventional $(\tau=0.54, \mathrm{p}=0.001)$ and organic systems $(\tau=0.58, \mathrm{p}<0.001)$. This was probably due to the high variability in fungicide use among no-till systems, which had a strong impact on 2016 wheat yield given the high disease pressure induced by the wet 
$404 \quad$ Farm structure

405 The farm structure indicators did not generally differ between systems (Table 3). The test for 406 livestock unit LSU gave a significant $p$-value ( $p=0.035$, Table $\mathrm{S} 4)$, but the post hoc test did 407 not reveal pairwise significant differences at a threshold of 0.05 (Table 3). The tendency was 408 however to a lower livestock value for no-till systems compared to conventional $(\mathrm{p}=0.077)$ 409 and organic ones $(\mathrm{p}=0.053)$ (Table S4). Utilised agricultural area UAA, annual work unit 410 AWU and diversity at the farm level in 2015-2016 farmDiv showed no differences between 411 cropping systems (Table S4).

\section{Crop diversification}

414 The number of leys, legumes and cover crops in the five-year crop rotation differed between 415 the three cropping systems (Table 3). The number of years with leys nbLeys was higher in the 416 organic system than conventional and no-till systems. This pointed to a difference in crop 417 rotation between this system on one side and conventional and no-till systems on the other 418 side (Figure S4). For the number of legumes nbLeg, the lowest value was observed in 419 conventional fields, compared to no-till and organic systems. Finally, no-till systems had 420 more often cover crops (nbCC) than organic systems, while conventional systems were 421 intermediate between no-till and organic, and not significantly different from both (Table 3).

422 Compared to the potential maximum number of cover crop cultivation (computed based on 423 the five-year crop rotation), conventional systems reached $38 \%$ of cover crop potential, no-till $42457 \%$ and organic $44 \%$. Organic systems had generally a lower number of potential cover crop 425 cultivation slots compared to conventional and no-till, due to the higher presence of leys, 426 which explained its higher percentage of actual to potential cover crops compared to 427 conventional systems.

428 Crop diversity cropDiv and crop rotation diversification rDiversification were not different 429 among the three cropping systems (Table 3, Figure 2A). 
431 Soil disturbance and protection

432 All Soil disturbance and protection indicators except field traffic showed differences between 433 systems (Table 3). The number of tillage nbTill and mechanical weeding nbWeed intervention during the period 2015-2016 differed between systems, with higher number of tillage operations in the organic than conventional systems. Only the organic systems included mechanical weeding. For the mean number of tillage and weeding interventions over the fiveyear crop rotation nbTW, and for the tillage intensity rating stir (Figure $2 \mathrm{~B}$ ), the highest values were observed for the organic system, followed by conventional, and then by no-till systems. The soil protection index soilP and soil cover sCover had higher values in the no-till systems compared to the conventional and organic ones. The estimated soil cover during the post-harvest, pre-sowing, period was significantly higher in no-till systems, with a mean value of $56 \%$, than in conventional and organic systems ( $28 \%$ and $18 \%$ respectively).

No differences between cropping systems were observed regarding total field traffic during the wheat cultivation period 2015-2016, with around 10 interventions on average.

In addition, the use of these Soil disturbance and protection indicators allowed to identify an outlier in the no-till farms, corresponding to the misclassification of one of the farms. For this farm, the actual cropping practices adopted by the farmer did not match the 'no-till' classification the farmer announced during the initial selection, as he practiced some minimum tillage.

\section{Organic matter inputs and nitrogen fertilisation}


456 nitrogen coming from organic amendments orgN, with higher value observed for organic

systems compared to conventional and no-till systems. In total, conventional and no-till

458 systems, with on average 160 and 147 equivalent $\mathrm{kg} \mathrm{N} / \mathrm{ha}$, showed higher amount of available

460 None of the five indicators linked to organic matter showed significant differences between 461 cropping systems at $\mathrm{p}<0.05$ (Table 3, Figure 2C). However, the $p$-value for the number of organic amendments nbOrg was at 0.055 , indicating a tendency of organic systems to have a 463 larger number of inputs (but not higher quantity).

\section{$474 \quad$ Yield}

475 Overall, mean wheat grain yield in 2016, as reported by the farmers, reached about $4.6 \mathrm{t} / \mathrm{ha}$ (at $47614 \%$ humidity). This represented about $80 \%$ of the wheat yield usually observed in the same 477 fields, for all three cropping systems. The reduced yield was due to an extremely wet spring in 478 2016. Indeed, the cumulated precipitation in April-May 2016 was $240 \mathrm{~mm}$ (Changins, west of

479 Switzerland) and $252 \mathrm{~mm}$ (Reckenholz, north-east), whereas the 30-year averages (1981480 2010) for April-May at the same stations are $153 \mathrm{~mm}$ and $193 \mathrm{~mm}$. Wheat yield in $2016 \mathrm{was}$ 481 higher in the conventional and no-till systems than in organic farming (Table 3). Relative 
yields over the crop rotation (2012-2016) differed significantly among all three cropping systems (Figure 2F): compared to the Swiss reference yields (for conventional practices), the mean relative yield was 1.05 for the conventional system, 0.93 for no-till and 0.70 for organic systems. This means that conventional yield in our study were on average $5 \%$ higher than 486 Swiss reference yield for the same crops, for the period 2012-2016. When comparing the 487 three systems together, taking the conventional system as the reference, no-till yield reached $48890 \%$ of the conventional yield, while organic yield was at $67 \%$ of the conventional one. For

\section{$492 \quad$ Multivariate analysis of primary indicators}

493 The principal component analysis performed on all the primary indicators allowed to 494 distinguish the three cropping systems on the three first components, despite high variability 495 within each system (Figure 3). The organic system was the most clearly delineated group, 496 while overlap was observed between conventional and no-till. The first axis (explaining 30\% 497 of variance) placed the conventional system intermediate between no-till and organic, while 498 the second axis (explaining $11 \%$ of variance) rather separated conventional system from no499 till and organic (Figure 3). The three indicators contributing most to the first axis were 500 mineral nitrogen fertilisation minN, number of herbicide treatments nbHerb and number of 501 weeding interventions nbWeed. For the second axis, the three most contributing indicators 502 were number of fungicide treatments nbFung, soil protection soilP and field traffic (Figure 3). 503

\section{Composite intensity indexes}

505 Significant differences between the three cropping systems were observed for five out of the 506 six composite indexes (Figure 4, Table 3). For the Crop diversification category, the two 507 composite indexes $\mathrm{I}_{\mathrm{PCA}}$ and $\mathrm{I}_{\mathrm{add}}$ were different between systems, but the index based on PCA 
508 showed higher values for the organic systems, while the index based on additive aggregation

509 was lower for the conventional systems (Figure 4). For Soil disturbance and protection, the

510 two composite indexes $\mathrm{I}_{\mathrm{PCA}}$ and $\mathrm{I}_{\mathrm{add}}$ differentiated the three systems, with higher values for

511 the organic system, followed by conventional, and then by no-till systems (Figure 4). For

512 Organic matter inputs and nitrogen fertilisation, $\mathrm{I}_{\mathrm{PCA}}$ showed higher values in the organic 513 systems, while $I_{\text {add }}$ was not different between the three systems (Figure 4).

\subsection{Comparison with other European countries}

Figure 5 shows the position of Switzerland and of the studied farms among 31 other European countries, according to the three farm structure indicators. Unfortunately, it was not possible to find separated data for conventional, no-till and organic systems, and thus our results are compared to overall European data. The mean utilised agricultural area in Switzerland is in the middle of the European distribution, whereas our study included somewhat larger farms. Annual working units were also similar to what is seen in other European countries. In comparison with Europe, the area under organic farming (\%UAA) in Switzerland in 2016 $(13.5 \%)$ is at the sixth position, with the highest value recorded in the neighbouring country of Austria (21.3\%).

To compare the cropping practices applied in Switzerland to what is done in Europe, we used the survey conducted by Herzog et al. (2006) in seven European countries (i.e. Belgium, 


\section{4. Discussion}

\subsection{Selection, definition and comparison of primary cropping practice indicators and} composite intensity indexes

In this study, the indicators were chosen to cover the main characteristics of cropping systems, especially at the field level, taking into account the potential availability and reliability of the data needed to compute the indicators. The topics covered here were similar to those appearing in other similar studies (e.g. Nkurunziza et al., 2017 and Gaudino et al., 2014), but included only so called 'driving forces' or 'causal' indicators (Bockstaller et al., 2015). Among the topics not addressed here, irrigation indicators were not included as generally not practiced on winter wheat fields in Switzerland. Indicators linked to P and $\mathrm{K}$ fertilisation, and five-year $\mathrm{N}$ fertilisation were not included either, but should be considered in a further development of this study. In Switzerland, P and K fertilisers are generally not applied annually but on a larger time scale, according to the duration of crop rotation or to the frequency of soil analysis. Thus the short term of this study would not have allowed to capture accurately $\mathrm{P}$ and $\mathrm{K}$ fertilisation practices. 
560 require information spread over several years. Therefore, the multiyear indicators presented

561 here were based on less detailed information, likely to be easily retrieved from the farmers. In this study, the utilisation of one year and five-year indicators allowed to show that the wheat

563 cultivation year studied seemed representative of the practices observed at the crop rotation

564 scale. The same approach was adopted by Nkurunziza et al. (2017), with detailed data

565 collected for the year of the study, and more general information collected for the preceding 566 years.

The studied indicators also differed in their complexity, i.e. the amount of data, reference values and assumptions needed to compute them. In this study, most of the complex indicators integrating several data and reference values were correlated with simpler indicators based on less data. (e.g. soil tillage intensity with the number of tillage and weeding interventions, soil cover with the simple soil protection indicator). The most complex indicators required a lot of reference data (e.g. reference yields, isohumic coefficients, ...) to be computed, which induced a necessary simplification of the complex farm practices, and increased indicator uncertainty. However, the set of indicators was tested here in one specific context, and we cannot exclude that complex indicators could prove to be necessary if tested with other data. For example, here the relative phytosanitary treatment frequency index, taking into account the applied dose and area (\% of field treated), was highly redundant with the number of treatments. This shows that in our specific study, most of pesticide applications were done at the full recommended dose and on the whole field. However, in other contexts it is highly likely that the more complex frequency index would provide more detailed

584 We also tested the potential of composite indexes to provide additional or simplify redundant 585 information compared to the primary indicators. Many studies recommend using simple as 
well as composite indicators to best describe cropping systems (Herzog et al., 2006:

587 Bockstaller et al., 2008: Castoldi and Bechini, 2010). Composite indexes have the advantage

to sum up different information into one unique variable and so to facilitate overall

conclusions and comparison between systems (e.g. Armengot et al., 2011, Blüthgen et al., 2012), while simple indicators remain essential to interpret the results more precisely. Many methods to build composite indexes exist (Nardo et al., 2005; Sadok et al., 2008), and two commonly used methods were investigated in this study.

Our results showed that the interpretation of the indexes could depend on the calculation method used. So, care should be taken when using composite indexes, and referring back to the individual components of the composite indexes is necessary to insure the proper interpretation of the results (Herzog et al., 2006). A good example of the problems which can occur when using the PCA method appeared for the Crop diversification category. While all the four individual indicators considered (frequency of leys, legumes, cover crops, and crop diversity) contribute to a higher diversification of the system, the first axis of the PCA composed a gradient with high diversity and cover crop frequency on one side, and high number of leys on the other side. This method here could not take into account the fact that different practices can achieve the same purpose, diversification in this case. Thus, this unconstrained method cannot guarantee that the composite index really shows the intended gradient. The PCA index can nevertheless be often meaningfully interpreted. In this case, cover crops contributed to higher diversity and thus pointed in the same direction, whereas the presence of rotational leys reduced diversity on a given time period by decreasing the number of main crops and cover crops that can be cultivated during this period. However, both can contribute to overall diversification. In contrast, in the additive aggregation method, the direction of interpretation of the individual indicators is a priori decided, which allows to construct meaningful gradients, even if the direction of some indicators is sometimes debatable. However, for the Soil disturbance and protection category, both methods produced 
612 similar composite indexes, showing that the PCA method could also be useful, provided that

613 the produced gradient is carefully checked. The PCA method is thus highly dependent on the

614 dataset on which it is based, while the additive aggregation method is mostly dependent on

615 the computation procedure, such as the normalisation or weighing method used. Depending

616 on the utilisation of the composite indexes, one or the other method should be preferred. For

617 example, when the objective is to aggregate further these indexes to produce a unique

618 multifunctionality index, the additive aggregation method is preferable for the first step, as it 619 allows controlling the direction of the indexes, and thus insuring proper interpretation of the

\subsection{Potential of indicators to characterise cropping systems}

\section{$\underline{\text { Farm level indicators }}$}

Including indicators common to European or international frameworks allowed to situate our study in a broader context, which could help the interpretation of the results. The farms in this study appear larger than the Swiss and European average. This could be partly explained by the fact that only lowland farms were selected for this study, excluding hill and mountain farms, which are generally smaller. This could also explain the lower values of livestock units in our study compared to the Swiss mean, but these values were in the range of what is seen in

Europe. In Switzerland, most conventional farms follow the 'Proof of Ecological

Performance' (PEP) guidance, which ensure, in principle, an equalised nutrient balance, diversified crop rotation and proper soil protection and pesticide treatment use (FOAG, 2018a). In this study, all conventional and no-till farms followed these prescriptions. This could explain some similarities between the conventional, no-till and organic systems, for example in terms of organic amendment inputs or crop rotation diversification. The application of these PEP guidelines in Switzerland could perhaps also explain the highest crop 
638 diversity observed by Herzog et al. (2006), whereas Switzerland was in line with the other

639 studied countries for nitrogen inputs and pesticide treatments.

\section{Primary cropping practice indicators and composite intensity indexes}

642 The set of the 31 indicators used here allowed to characterise the three cropping systems

643 studied. Around one third of them did not show differences between systems, while the others

644 showed a variety of patterns of differences between systems. An important intra-system

645 variability was also observed for most of the indicators. This demonstrates the importance of

646 using cropping practice indicators rather than cropping system classification to assess and

647 understand the impact of practices, particularly in broadly defined cropping systems

648 (Armengot et al., 2011; Nkurunziza et al., 2017; Therond et al., 2017).

The three simpler Crop diversification indicators differentiated the three systems, while diversity and rotation diversification were similar between systems, with high within-system

variability. However, overall, the indicators pointed to a lower diversification of conventional systems, which was confirmed by the composite index based on additive aggregation. This shows that no-till systems including cover crops as well as organic systems with rotational leys allow to increase diversification, a key factor of sustainable agriculture intensification (Smith et al., 2017).

The Soil disturbance and protection category was the one showing the major differences between systems. As expected, no-till systems had higher soil protection values compared to conventional and organic systems. Interestingly, these indicators also separated organic systems, and the composite indexes clearly showed the same pattern. To compensate for the absence of herbicide use, intense mechanical weeding was generally observed in organic 663 fields. This poses the question of the balance of the benefits of reduced pesticide products 
664 utilisation and the potential negative effects of increased soil disturbance in organic farming.

665 Minimum soil tillage in organic farming is a challenge, but the development of more specific and efficient tillage implements and the adoption of cover crop cultivation, which was low in

668 farming (Buchanan et al., 2016; Cooper et al., 2016).

669 In contrast, indicators linked to Organic matter inputs, included the composite index based on 670 additive aggregation, were similar between the three cropping systems. This finding is surprising as organic systems are generally thought to provide more organic matter to the soil, through organic amendments or inputs due to the introduction of leys in the rotation. In the organic system, the level of fertilisation was generally low, with an estimated $\mathrm{N}$ input to the 2016 wheat (61 kgN/ha, from organic source) less than half the Swiss (conventional) reference standard for $\mathrm{N}$ fertilisation of winter wheat $(140 \mathrm{kgN} / \mathrm{ha})$, while conventional and no-till systems showed similar, higher, values $(160 \mathrm{kgN} / \mathrm{ha}$ and $147 \mathrm{kgN} / \mathrm{ha}$, from both mineral and organic sources).

Crop protection indicators also allowed the differentiation of both no-till and organic systems compared to conventional ones. As expected, no pesticide treatments were used in the organic fields which were thus easily identified. The frequency of herbicide treatments was higher in no-till compared to conventional systems. The higher reliance on total herbicides in no-till system has been documented (Melander et al., 2013), and remains the principal environmental challenge with no-till. Minimum tillage, such as shallow tillage $(5 \mathrm{~cm})$ or strip till, along with the intensification of cover crop utilisation, could be a way of reducing herbicide use while preserving soil, which is a solution currently considered by some farmers. Less fungicide treatments were applied in no-till fields, reflecting the fact that they were more often managed according to so called extensive farming programs that forbids the use of pesticides other than herbicides. Except from farmers adopting no-till practices to save labour time, no-till farmers 
are generally adopting these practices to reduce the impact of agriculture on the environment,

which explain their higher compliance with these extensive farming programs.

693 which can be explained by the fact that this system has more specific rules than the no-till or

694 conventional systems and bans several practices, principally mineral fertilisation and chemical 695 crop protection. In contrast, conventional and no-till systems showed higher overlap in their 696 practices, especially in terms of crop diversity, rotation diversification and fertilisation. This 697 showed that, in this study, focusing on the 'no-till' criterion did not implicitly co-select other 698 specific cropping practices.

700 Yield and relative yield cannot be considered as cropping practices like the other indicators 701 presented here, but are the main outcomes of these practices and fundamental to interpret their 702 sustainability. The no-till fields showed a mean decrease of yield of $10 \%$ compared to 703 conventional ones on the five-year crop rotation, which is similar to what has been previously 704 shown (Pittelkow et al., 2015a). This difference was, however, not significant for the 2016 wheat yield, and was partially linked to the compliance of farmers with the extensive farming programs mentioned earlier. Indeed, extensive conventional fields showed lower yield than intensive conventional ones, and thus more similar to no-till yields. In contrast, no difference was observed for extensive and intensive no-till yields. A yield decrease in the initial years of transition to no-till is generally expected, while the yield gap generally fills up after some years (Soane et al., 2012; Pittelkow et al., 2015b). The cover crop frequency tended to be higher in new no-till systems, pointing probably to a growing awareness of the importance of integrating no-till in an ensemble of sustainable practices amongst the younger no-till farmers compared to pioneer ones. A relative mean yield decrease of about 33\% was observed in 14 organic fields compared to conventional ones, which is slightly higher than what has been 
715 shown in global meta-analyses ( $26 \%$ for cereals with high variability, de Ponti et al., 2012;

716 Seufert et al., 2012). The yield difference between organic and conventional systems was even higher when looking only at the 2016 wheat yield, which showed a decrease of $40 \%$.

719 detrimental for organic fields. Despite the low mean yield in the organic system, it is

720 worthwhile mentioning that the highest organic yields were higher than some of the yields

721 obtained in conventional or no-till systems. This showed that depending on the conditions and on the practices implemented, organic yield could achieve a reasonable productivity.

\subsection{Conclusions}

In this study, we employed 31 quantitative primary indicators and six composite indexes to describe the cropping practices in three different systems, i.e. conventional, no-till and organic systems. The set of indicators presented here integrates indicators of different complexity and time scale. It allows to characterise the three cropping systems and highlight differences as well as similarity within systems and within system variability. The composite indexes, based on simple primary indicators, proved to be useful to synthesise information of different indicators and delineate the systems. However, the method used to compute the indexes has an influence on their interpretation and should be carefully chosen. Here, the more complex primary indicators were often correlated with simpler ones or with the composite indexes, challenging their usefulness, but it cannot be excluded that they can prove to be more useful for different datasets or contexts. Retaining a combination of simple and more complex indicators to obtain a broad picture of the cropping practices adopted is thus recommended.

This study has demonstrated that an exhaustive and explicit description of the cropping practices involved in what is generally classified as different cropping systems is crucial to better understand the potential influence of these systems on yield or soil properties. For 
741 example, knowing the tillage intensity applied in organic fields would be of crucial

742 importance to analyse and predict soil organic matter evolution. While the comparison of systems in terms of yield, soil properties or their influence on the environment is highly

744 relevant, this study has shown that it is crucial to describe precisely and quantitatively the

745 cropping practices involved to avoid any misinterpretation based on supposed or non-

746 acknowledged differences.

747

748

\section{Acknowledgements}

750 The authors thank Cindy Bally, Thibault Granger, Julia Hess, Marcel Meyer, Kexing Liu, Joel

751 Hofer and all the persons who helped for field and lab work. Many thanks also to the two

752 anonymous reviewers who provided relevant comments on previous versions of the

753 manuscript. This study was funded by the Swiss National Science Foundation in the

754 framework of the National Research Program 'Sustainable Use of Soil as a Resource' (NRP

755 68) [grant 406840-161902]. 


\section{References}

759 Agroscope, 1996. Méthodes de référence des stations de recherche Agroscope, volume 1: Analyse de terre et du substrat pour conseil de fumure.

\section{4}

765

766

Armand, R., Bockstaller, C., Auzet, A.-V., Van Dijk, P., 2009. Runoff generation related to intra-field soil surface characteristics variability. Application to conservation tillage context. Soil Till. Res. 102, 27-37.

Armengot, L., José-María, L., Blanco-Moreno, J.M., Bassa, M., Chamorro, L., Sans, F.X., 2011. A novel index of land use intensity for organic and conventional farming of Mediterranean cereal fields. Agron. Sustain. Dev. 31:699.

Bechini, L., Castoldi, N., 2009. On-farm monitoring of economic and environmental performances of cropping systems: results of a 2-year study at the field scale in northern Italy. Ecol. Indic. 9:1096-1113.

Blüthgen, N., Dormann, C.F., Prati, D., et al., 2012. A quantitative index of land-use intensity in grasslands: integrating mowing, grazing and fertilization. Basic Appl. Ecol., 13:207220.

Bockstaller, C., Girardin, P., 2000. Using a crop sequence indicator to evaluate crop rotations, in: 3rd International Crop Science Congress 2000 ICSC. Hambourg, p. 195.

Bockstaller, C., Girardin, P., Van der Werf, H.G.M., 1997. Use of agroecological indicators for the evaluation of farming systems. Eur. J. Agron. 7, 261-270.

Bockstaller, C., Guichard, L., Makowski, D., Aveline, A., Girardin, P., Plantureux, S., 2008. Agri-environmental indicators to assess cropping and farming systems. A review. Agron. Sustain. Dev. 28, 139-149.

Buchanan, A.L., Kolb, L.N., Hooks, C.R.R., 2016. Can winter cover crops influence weed density and diversity in a reduced tillage vegetable system? Crop Prot. 90, 9-16. 
782 Büchi, L., Valsangiacomo, A., Burel, E., Charles, R., 2016. Integrating simulation data from a crop model in the development of an agri-environmental indicator for soil cover in Switzerland. Eur. J. Agron. 76, 149-159.

Castoldi, N., Bechini, L., 2010. Integrated sustainability assessment of cropping systems with agro-ecological and economic indicators in northern Italy. Eur. J. Agron. 32:59-72.

Cooper, J., Baranski M., et al. 2016. Shallow non-inversion tillage in organic farming maintains crop yields and increases soil C stocks: a meta-analysis. Agron. Sustain. Dev. $36,1-20$.

CSICM, 2010. Directive suisse 2010 de la branche sur la qualité du compost et du digestat. Commission suisse de l'inspectorat du compostage et de la méthanisation, $40 \mathrm{pp}$.

CTACF, 2006. Mise en oeuvre de la technique du Bois Raméal Fragmenté (BRF) en agriculture wallonne. Centre des Technologies Agronomiques Communauté Française, $168 \mathrm{pp}$.

de Ponti, T., Rijk, B., van Ittersum, M.K., 2012. The crop yield gap between organic and conventional agriculture. Agric. Syst. 108, 1-9.

Eurostat, 2018. Key to European Statistics. Agriculture Data [online]. Available at: http://ec.europa.eu/eurostat/web/agriculture/data/main-tables (accessed 01.06.18.).

FAO, 2018. Food and Agriculture Organization of the United Nations: Conservation Agriculture [online]. Available at: http://www.fao.org/conservation-agriculture [accessed 12.07.18].

FOAG, 2018a. Federal Office for Agriculture. Prestations écologiques requises [online]. Available at: https://www.blw.admin.ch/blw/fr/home/instrumente/direktzahlungen/oekologischerleistungsnachweis.html [accessed 23.07.2018].

FOAG, 2018b. Federal Office for Agriculture. Index des produits phytosanitaires [online]. Available at: https://www.psm.admin.ch/fr/produkte [accessed 23.07.2018]. 
FSO, 2016. Federal Statistical Office. Relevé des structures agricoles 2016 [online]. Available at: https://www.bfs.admin.ch/bfs/en/home/statistics/catalogues-databases/pressreleases.assetdetail.2348899.html [accessed 03.02.2019].

Gaudino, S., Goia, I., Borreani, G., Tabacco, E., Sacco, D., 2014. Cropping system intensification grading using an agro-environmental indicator set in northern Italy. Ecol. Indic. 40:76-89.

Geiger, F., Bengtsson, J., Berendse, F., et al., 2010. Persistent negative effects of pesticides on biodiversity and biological control potential on European farmland. Basic Appl. Ecol. 11:97-105.

Herzog, F., Steiner, B., Bailey, D., Baudry, J., Billeter, R., Bukacek, R., De Blust, G., De Cock, R., Dirksen, J., Dormann, C.F., De Filippi, R., Frossard, E., Liira, J., Schmidt, T., Stöckli, R., Thenail, C., van Wingerden W., Bugter, R. 2006. Assessing the intensity of temperate European agriculture at the landscape scale. Eur. J. Agron. 165-181.

Hossard, L., Guichard, L., Pelosi, C., Makowski, D., 2017. Lack of evidence for a decrease in synthetic pesticide use on the main arable crops in France. Sci. Total Environ. 575:152161.

Kirchmann, H., Kätterer, T., Bergström, L., Börjesson, G., Bolinder, M.A., 2016. Flaws and criteria for design and evaluation of comparative organic and conventional cropping systems. Field Crops Res. 186, 99-106.

Knapp, S., van der Heijden, M.G., 2018. A global meta-analysis of yield stability in organic and conservation agriculture. Nat. Commun. 9, 3632.

Lilley, J.M., Moore, A.D., 2009. Trade-offs between productivity and ground cover inmixed farming systems in the Murrumbidgee catchment of New South Wales.Anim. Prod. Sci. $49,837-851$.

Mäder, P., Fliessbach, A., Dubois, D., Gunst, L., Fried, P., Niggli, U., 2002. Soil fertility and biodiversity in organic farming. Science 296, 1694-1697. 
834 Melander, B., Munier-Jolain, N., Charles, R., Wirth, J., Schwarz, J., van der Weide, R., 835 Bonin, L., Kryger Jensen, P., Kudsk, P., 2013. European perspectives on the adoption of 836 non-chemical weed management in reduced tillage systems for arable crops. Weed Technol. 27, 231-240.

Migliorini, P., Wezel, A., 2017. Converging and diverging principles and practices of organic agriculture regulations and agroecology. A review. Agron. Sustain. Dev. 37-63.

Nardo M., Saisana M., Saltelli A., Tarantola S., 2005. Tools for composite indicators building. Joint Research Center, European Commission, Ispra (Italy), p. 134.

Nkurunziza, L., Changtham, I.R., Watson, C.A., Marstorp, H., Oborn, I., Bergkvist, G., Bengtsson, J., 2017. Understanding effects of multiple farm management practices on barley performance. Eur. J. Agron. 90, 43-52.

Oksanen, J., Blanchet, F.G., Friendly, M., Kindt, R., Legendre, P., Mcglinn, D., Minchin, P.R., O’Hara, R.B.,Simpson, G.L., Solymos, P., Stevens, M.H.H, Szoecs, E., Wagner, H., 2017. vegan: Community Ecology Package. R package version 2.4-2.

Pelzer, E., Fortino, G., Bockstaller, C., Angevin, F., Lamine, C., Moonen, C., Vasileiadis, V., Guérin, D., Guichard, L., Reau, R., Messéan, A., 2012. Assessing innovative cropping systems with DEXiPM, a qualitative multi-criteria assessment tool derived from DEXi. Ecol. Indic. 18, 171-182.

Pittelkow, C.M., Liang, X., Linquist, B.A., van Groenigen, K.J., Lee, J., Lundy, M.E., van Gestel, N., Six, J., Venterea, R.T., van Kessel, C., 2015a. Productivity limits and potentials of the principles of conservation agriculture. Nature 517, 365-368.

Pittelkow, C.M., Linquist, B.A., Lundy, M.E., Liang, X., van Groenigen, K.J., Lee, J., van Gestel, N, Six, J., Venterea, R.T., van Kessel, C., 2015b. When does no-till yield more? A global meta-analysis. Field Crop Res. 183, 156-168. 
858 Ponisio, L.C., M'Gonigle, L.K., Mace, K.C., Palomino, J., de Valpine, P., Kremen, C., 2015. Diversification practices reduce organic to conventional yield gap. Proc. R. Soc. B 282, 20141396.

R Core Team, 2018. R: A language and environment for statistical computing. R Foundation for Statistical Computing, Vienna, Austria, http://www.R-project.org

Reganold, J.P., Wachter, J.M. 2016. Organic agriculture in the twenty-first century. Nat. Plants 2, 15221.

Sadok, W., Angevin, F., Bergez, J.-. E., Bockstaller, C., Colomb, B., Guichard, L., Reau, R., Doré, T., 2008. Ex ante assessment of the sustainability of alternative cropping systems: guidelines for identifying relevant multi-criteria decision aid methods. Agron. Sustain. Dev. 28, 163-174.

Seufert, V., Ramankutty, N., Foley, J.A., 2012. Comparing the yields of organic and conventional agriculture. Nature 485, 229-232.

Seufert, V., Ramankutty, N., 2017. Many shades of gray-The context-dependent performance of organic agriculture. Science Advances 3, e1602638.

Sinaj, S., Richner, W., 2017. Principes de fertilisation des cultures agricoles en Suisse (PRIF 2017). Agrarforschung 8(6).

Smith, A., Snapp, S.S., Chikowo, R., Thorne, P., Bekunda, M., Glover, J., 2017. Measuring sustainable intensification in smallholder agroecosystems: a review. Glob. Food Secur. $12,127-138$.

Soane, B.D., Ball, B.C., Arvidsson, J., Basch, G., Moreno, F., Roger-Estrade, J., 2012. No-till in northern, western and south-western Europe: a review of problems and opportunities for crop production and the environment. Soil Till. Res. 118, 66-87.

Therond, O., Duru, M., Roger-Estrade, J., Richard, G., 2017. A new analytical framework of farming system and agriculture model diversities. A review. Agron. Sustain. Dev. $37: 21$. 
884 USDA, 2012. Revised Universal Soil Loss Equation, Version 2 (RUSLE2). Natural Resources

886 Zahm, F., Viaux, P., Vilain, L., Girardin, P., Mouchet, C., 2008. Assessing farm sustainability $888 \quad$ on farms. Sust. Dev. 16:271-281.

\begin{abstract}
with the IDEA method - From the concept of agriculture sustainability to case studies
\end{abstract}


Table and figure legends

Table 1 List of the 31 cropping practice indicators used to describe cropping systems. 'Time scale' indicates if the indicator is computed with data coming only from the focal year 2015$2016\left(' 1 y^{\prime}\right)$ or from data collected for the five-year crop rotation ('5 y').

Table 2 List of primary indicators selected for the computation of the two composite indexes, for each thematic category, and complex or compound primary indicators used for comparison. Indicators preceded by a '-" were reversed for the computation of the additive aggregation index $\mathrm{I}_{\text {add }}$. See Table 1 for the meaning of the indicator abbreviations.

Table 3 Mean values of the 31 primary indicators and six composite indexes for the three cropping systems, and patterns of differences between systems as indicated by the Tukey HSD post-hoc pairwise tests. 'conv': conventional farming, 'nt': no-till farming, 'org': organic farming.

Figure 1 Principal component analyses (field projection, scaling 2) on the indicator subsets, A. Farm structure, B. Crop diversification, C. Soil disturbance and protection, D. Organic matter inputs and nitrogen fertilisation, E. Crop protection. As for yield only two indicators were used, F. shows the pairwise relationship between wheat yield 2016 [t/ha] and relative yield over the five-year crop rotation. The plain line shows the linear regression between these two variables. The dashed horizontal line shows the Swiss reference yield for winter wheat (6 $\mathrm{t} / \mathrm{ha}$ ) and the dashed vertical line a relative yield which is equal to reference yields on average. Blue points correspond to conventional systems, red points to no-till systems and green points to organic systems. Correspondence between abbreviations and indicator names are given in Table 1. 
917 Figure 2 Differences between cropping systems for six indicators. A. crop rotation

918 diversification (rDiversification), B. soil tillage intensity (stir), C. quantity of organic

919 amendment inputs (qOrg) [kg OM/ha], D. total nitrogen fertilisation (totN) [kg N/ha], E.

920 relative herbicide treatment intensity (rHerb), F. relative yield (relY). 'conv': conventional

921 systems, 'nt': no-till systems, 'org': organic systems. Different letters above the boxes show

922 significant $(\mathrm{p}<0.05)$ pairwise differences between systems.

Figure 5 Comparison of the three farm structure indicators and of area under organic farming 938 (\% UAA) with mean data from Switzerland and European countries. Data were obtained from 939 the Eurostat website. Blue points correspond to conventional systems, red points to no-till 940 systems and green points to organic systems. On each box, ' $\mathrm{CH}$ ' shows the position of 941 Switzerland in the European dataset. 


\section{Supplementary Material}

945 Table S1 List and description of the 60 farms included in the study. 'Mean temperature' and 946 'Rainfall' are given as average values over the two years 2015 and 2016. 'Soil texture' gives 947 texture classes according to the ISSS system. 'Program' refers to compliance to specific 948 'integrated' (no pesticides except herbicides) or 'organic' programs in 2016. 'UAA' is for 949 utilised agricultural area. 'Fertilisation' indicates what kind of fertilisation was used during 950 the five-year crop rotation: 'min' = mineral only, 'org' = organic only, 'min-org' = mixed 951 mineral and organic. The conventional farm indicated in light grey was removed from the 952 analyses due to missing survey data.

953

954 Table S2 Data collected in the questionnaire survey (rows), filled in by the farmers, and used 955 to compute the 31 cropping practice indicators (columns). The crosses indicate which data has 956 been used for which indicator.

958 Table S3 Isohumic coefficients and nitrogen availability of organic amendments used in the 959 computation of the organic amendment inputs (qOrg), total organic inputs (totOrg), nitrogen 960 organic fertilisation ( $\operatorname{orgN}$ ) and total nitrogen fertilisation indicators (totN).

962 Table S4 Mean values and standard errors of the 31 indicators for the three cropping systems, 963 and p-values from the overall analysis of variance ('global') and from the Tukey HSD post964 hoc pairwise test. 'conv': conventional farming, 'nt': no-till farming, 'org': organic farming. 965 
966 Figure S1 Map of Switzerland showing the geographic position of the 60 fields. Blue points correspond to conventional systems, red points to no-till systems and green points to organic 968 systems.

Figure S2 Texture triangle (ISSS system) showing the texture $(0-20 \mathrm{~cm})$ of the 60 fields. Blue points correspond to conventional systems, red points to no-till systems and green points to organic systems.

Figure S3 Principal component analyses (field projection, scaling 2) used for the computation of the composite indexes for A. Crop diversification, B. Soil disturbance and protection, and C. Organic matter inputs and nitrogen fertilisation. Blue points correspond to conventional systems, red points to no-till systems and green points to organic systems. Correspondence between abbreviations and indicator names are given in Table 1.

Figure S4 A. Crop frequency for the studied fields, for the three cropping systems ('conv': conventional, 'nt': no till, 'org': organic). Crops are grouped into types. B. Categorisation of the crop rotation along three main types: 1. rotations with a cereal every two years, 2 . rotations including leys, and 3. other type of rotations.

Figure S5 Relative yield indicator as a function of time since the beginning of A. no-till practice and B. organic practice. In panel A, the numbers above the points indicate the number of cover crops cultivated the past 5 years (number of cover crop ' $\mathrm{nbCC}$ ' indicator).

Figure S6 Comparison of Switzerland with six other European countries in terms of crop diversity, nitrogen fertilisation and pesticide inputs. On each box, ' $\mathrm{CH}$ ' shows the position of Switzerland. On the left of each box, the two-letter code of each other country is indicated, 
992 BE: Belgium, CZ: Czech Republic, EE: Estonia, FR: France, DE: Germany, NL: Netherlands.

993 The data come from Herzog et al. (2006). 


\begin{tabular}{|c|c|c|c|}
\hline Indicator & Abbreviation & $\begin{array}{l}\text { Time } \\
\text { scale }^{a}\end{array}$ & \\
\hline \multicolumn{4}{|l|}{ Farm structure } \\
\hline utilised agricultural area [ha] & UAA & - & \\
\hline annual working unit & AWU & - & a value of 1 corresponds to 1 person working full time on the farm \\
\hline livestock unit & LSU & - & a value of 1 corresponds to 1 dairy cow per hectare \\
\hline diversity at farm level 2016 & farmDiv & $1 \mathrm{y}$ & $\mathrm{nb}$ of crops, meadows or fallows at the farm level in 2016 \\
\hline \multicolumn{4}{|l|}{ Crop diversification } \\
\hline number of years with ley & nbLeys & $5 y$ & $\mathrm{nb}$ of years with ley in the 5 year rotation \\
\hline number of legume crops & nbLeg & $5 y$ & $\mathrm{nb}$ of legume cultivation (main and cover crop) in the 5 year rotation \\
\hline number of cover crops & $\mathrm{nbCC}$ & $5 y$ & $\mathrm{nb}$ of cover crop cultivation in the 5 year rotation \\
\hline crop diversity at field level (rotation) & cropDiv & $5 y$ & $\mathrm{nb}$ of crops in the 5 year rotation \\
\hline crop rotation diversification & rDiversification & $5 y$ & index taking into account crop diversity, preceding crop and time to previous wheat \\
\hline \multicolumn{4}{|l|}{ Soil disturbance and protection } \\
\hline field traffic & traffic & $1 \mathrm{y}$ & $\mathrm{nb}$ of machinery passages (tillage, seeding, weeding, treatments, fertilisation) \\
\hline number of tillage $2015-2016$ & nbTill & $1 \mathrm{y}$ & \\
\hline $\begin{array}{l}\text { number of weeding } 2015-2016 \\
\text { number of tillage and weeding interventions }\end{array}$ & nbWeed & $1 \mathrm{y}$ & \\
\hline 2012-2016 & nbTW & $5 \mathrm{y}$ & mean number of tillage and weeding interventions over the crop rotation \\
\hline soil protection index & soilP & $5 y$ & index linked to the type of tillage (plough, minimum, no till) \\
\hline soil tillage intensity & stir & $1 \mathrm{y}$ & index based on the soil disturbance intensity of each implement (e.g plough=81) \\
\hline soil cover & sCover & $1 \mathrm{y}$ & mean soil cover during the period preceding wheat seeding \\
\hline \multicolumn{4}{|l|}{ Organic matter inputs and nitrogen fertilisation } \\
\hline crop residue exportation & resExp & $5 y$ & $\mathrm{nb}$ of time residues were exported during the 5 year crop rotation \\
\hline number of organic amendments & nbOrg & $5 y$ & $\mathrm{nb}$ of organic amendements \\
\hline organic amendment inputs [kg OM/ha] & qOrg & $5 y$ & quantity of organic matter inputs through amendements \\
\hline organic input from crops [kg OM/ha] & cropOrg & $5 y$ & quantity of organic matter inputs through crop residues \\
\hline residues) [kg OM/ha] & totOrg & $5 y$ & total quantity of organic inputs \\
\hline mineral nitrogen fertilisation [kg N/ha] & $\min N$ & $1 \mathrm{y}$ & quantity of mineral nitrogen fertilisers \\
\hline organic nitrogen fertilisation [kg N/ha] & $\operatorname{orgN}$ & $1 \mathrm{y}$ & quantity of available nitrogen through organic fertilisation \\
\hline
\end{tabular}


total nitrogen fertilisation [kg N/ha]

Crop protection

number of herbicide treatment

number of fungicide treatment

total number of treatments

herbicide treatment frequency index

total treatment frequency index

Yield

wheat yield 2016 [t/ha]

relative yield 2012-2016
totN
$1 \mathrm{y}$
nbHerb $\quad 1 \mathrm{y} \quad \mathrm{nb}$ of herbicide treatments
nbFung $\quad 1 \mathrm{y} \quad \mathrm{nb}$ of fungicide treatments
nbTreat $\quad 1 \mathrm{y} \quad$ total number of treatments (herbicide, fungicide, molluscicide, growth regulator)
rHerb $\quad 1 \mathrm{y} \quad$ sum of the ratios of applied herbicide dose over recommended dose
rTreat $\quad 1 \mathrm{y} \quad$ sum of the ratios of applied treatment dose over recommended dose

a 1 or 5 y: 1 year (from the harvest of the preceding crop to the wheat harvest) or 5 years (crop rotation) 
Primary indicators used for composite intensity indexes

Thematic category Crop diversification

Soil disturbance and protection + nbLeys +nbLeg +nbCC +cropDiv

+ traffic

$+n b T$ Till

+ nbWeed

-soilP

Organic matter inputs and nitrogen fertilisation

Crop protection

+resExp +nbOrg +qOrg

-cropOrg

$+\min N$

Yield
Complex primary indicators

rDiversification

stir

sCover

totN

rTreat

relY 
Table 3

Indicator

or

Farm structure

utilised agricultural area [ha]

annual working unit

livestock unit

diversity at farm level 2016

Crop diversification

nb years with ley

nb legume crops

nb cover crops

crop diversity at field level (rotation)

crop rotation diversification

composite index based on PCA

composite index based on additive

aggregation

Soil disturbance and protection

\section{field traffic}

nb tillage 2015-2016

nb weeding 2015-2016

nb tillage and weeding interventions 2012-

2016

soil protection index

soil tillage intensity

soil cover

composite index based on PCA

composite index based on additive

aggregation

Organic matter inputs and nitrogen fertilisation

crop residue exportation

nb organic amendments

organic amendment inputs [kg OM/ha]

organic input from crops [kg OM/ha]

Abbreviation

Overall means
conv nt

org

Differences between systems

all different $^{a} \quad$ conv different $^{b}$ nt different ${ }^{c}$ org different ${ }^{d}$ no difference

$\begin{array}{llll}\text { UAA } & 62 & 44 & 41\end{array}$

$\begin{array}{llll}\text { AWU } & 2.6 & 1.9 & 2.0\end{array}$

$\begin{array}{llll}\text { LSU } & 0.70 & 0.27 & 0.73\end{array}$

$\begin{array}{llll}\text { farmDiv } & 6.58 & 6.25 & 7.15\end{array}$

$\begin{array}{llll}\text { nbLeys } & 0.26 & 0.30 & 1.25\end{array}$

$\begin{array}{llll}\text { nbLeg } & 1.16 & 2.05 & 2.35\end{array}$

$\begin{array}{llll}\text { nbCC } & 1.16 & 1.90 & 0.85\end{array}$

$\begin{array}{llll}\text { cropDiv } & 4.63 & 5.00 & 4.30\end{array}$

rDiversification $\quad \begin{array}{llll}6.17 & 7.18 & 7.00\end{array}$

$\begin{array}{lll}-0.08 & -0.22 & 0.30 \\ 0.28 & 0.40 & 0.39\end{array}$

$\begin{array}{lll}10.5 & 9.1 & 9.8\end{array}$

$\begin{array}{llll}\text { nbTill } & 1.32 & 0.40 & 2.55\end{array}$

$\begin{array}{llll}\text { nbWeed } & 0.00 & 0.00 & 2.35\end{array}$

$\begin{array}{llll}\text { nbTW } & 2.32 & 0.18 & 4.06\end{array}$

$\begin{array}{llll}\text { soilP } & 1.63 & 4.72 & 1.82\end{array}$

$\begin{array}{llll}\text { stir } & 94 & 24 & 139\end{array}$

$\begin{array}{llll}\text { sCover } & 0.28 & 0.56 & 0.18\end{array}$

$0.02 \quad-0.52 \quad 0.50$

$\begin{array}{lll}0.41 & 0.13 \quad 0.57\end{array}$

$\begin{array}{llll}\text { resExp } & 2.37 & 1.60 & 2.75\end{array}$

nbOrg $\quad 5.05 \quad 5.05 \quad 5.40$

$\begin{array}{llll}\text { qOrg } & 465 & 435 & 470\end{array}$

$\begin{array}{llll}\text { cropOrg } & 683 & 726 & 708\end{array}$


total organic inputs [kg OM/ha]

$\begin{array}{llll}\text { totOrg } & 1148 & 1161 & 1178\end{array}$

mineral nitrogen fertilisation [kg N/ha]

organic nitrogen fertilisation [kg N/ha]

$\min N$

141

$127 \quad 0$

\section{total nitrogen fertilisation [kg N/ha]}

$\operatorname{org} \mathrm{N}$

19

$\begin{array}{ll}127 & 0 \\ 20 & 61\end{array}$

composite index based on PCA

composite index based on additive

Crop protection

\section{$\mathrm{nb}$ herbicide treatment}

nbHerb

$\begin{array}{lll}1.11 & 2.30 & 0.00\end{array}$

nb fungicide treatment

total number of treatments

$\begin{array}{llll}\text { nbFung } & 1.16 & 0.30 & 0.00\end{array}$

$\begin{array}{llll}\text { nbTreat } & 3.11 & 2.70 & 0.00\end{array}$

herbicide treatment frequency index

2.32

total treatment frequency index

rTreat

2.77

$2.71 \quad 0.00$

$\mathrm{X}$

Yield

wheat yield 2016 [t/ha]

yield

5.6

4.9

3.4

significant differences between the three groups

b significant differences between conv-nt and conv-org, but not nt-org

c significant differences between nt-conv and nt-org, but not conv-org

${ }^{d}$ significant differences between org-conv and org-nt, but not conv-nt

* significant difference between nt-org, but not between conv-nt and conv-org 


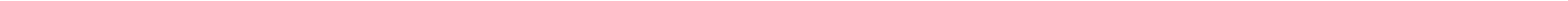




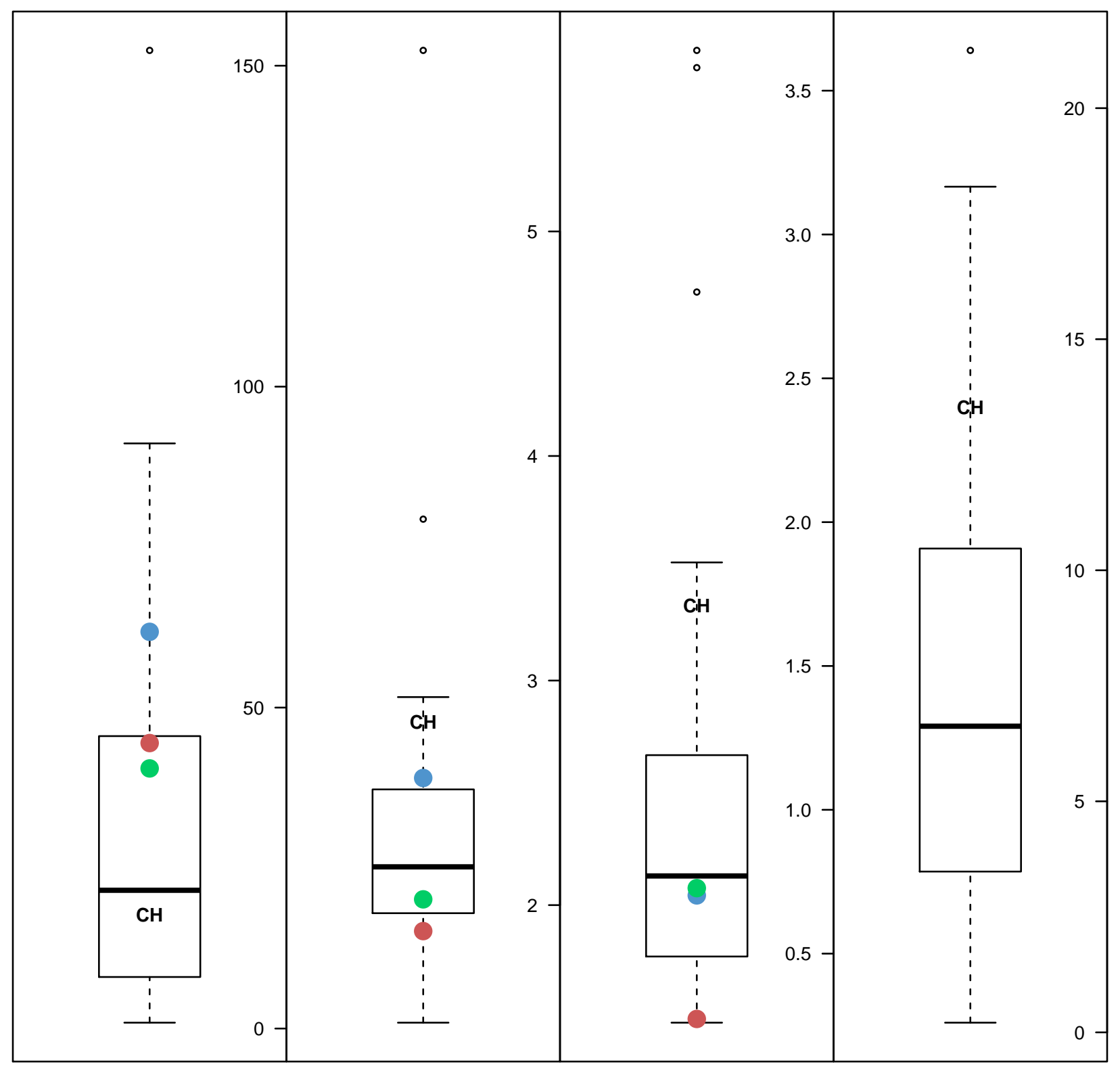


Table S1 List and description of the 60 farms included in the study. 'Mean temperature' and 'Rainfall' are given as average values over the two years 2015 and 2016. 'Soil texture' gives texture classes according to the ISSS system. 'Program' refers to compliance to specific 'integrated' (no pesticides except herbicides) or 'organic' programs in 2016. 'UAA' is for utilised agricultural area. 'Fertilisation' indicates what kind of fertilisation was used during the five-year crop rotation: 'min' = mineral only, 'org' = organic only, 'min-org' $=$ mixed mineral and organic. The conventional farm indicated in light grey was removed from the analyses due to missing survey data.

\begin{tabular}{|c|c|c|c|c|c|c|c|c|c|}
\hline Cropping system & Canton & Altitude [m] & Mean temp $\left[{ }^{\circ} \mathrm{C}\right]$ & Rainfall [mm] & Soil texture & Program & UAA [ha] & Fertilisation & Livestock unit \\
\hline conv & GE & 476 & 11.3 & 879 & light clay & integrated & 102 & min-org & $0.5<>1$ \\
\hline conv & GE & 427 & 10.8 & 793 & silty clay loam & integrated & 84 & $\min$ & $0<>0.5$ \\
\hline conv & GE & 361 & 11.7 & 680 & loam & integrated & 110 & $\min$ & $0<>0.5$ \\
\hline conv & GE & 423 & 11.3 & 786 & loam & none & 190 & min-org & $0.5<>1$ \\
\hline conv & GE & 427 & 11.7 & 680 & clay loam & integrated & 63 & $\min$ & 0 \\
\hline conv & VD & 485 & 10.6 & 743 & clay loam & none & 106 & $\min$ & $0<>0.5$ \\
\hline conv & VD & 457 & 11.5 & 1035 & clay loam & none & 63 & min-org & $>1$ \\
\hline conv & VD & 754 & 9.9 & 1002 & loam & integrated & 33 & min-org & $0.5<>1$ \\
\hline conv & VD & 437 & 10.4 & 778 & clay loam & none & 45 & $\min$ & $0<>0.5$ \\
\hline conv & VD & 554 & 10.1 & 805 & loam & none & 43 & min-org & $0<>0.5$ \\
\hline conv & $A G$ & 383 & 10.2 & 934 & loam & integrated & 25 & min-org & $0<>0.5$ \\
\hline conv & LU & 479 & 9.3 & 1080 & loam & none & 30 & min-org & $>1$ \\
\hline conv & $L U$ & 506 & 9.3 & 1080 & clay loam & - & - & - & \\
\hline conv & $\mathrm{ZH}$ & 408 & 10.4 & 967 & clay loam & none & 18 & min-org & $0<>0.5$ \\
\hline conv & $\mathrm{ZH}$ & 518 & 10.4 & 1322 & clay loam & none & 33 & min-org & $>1$ \\
\hline conv & $\mathrm{ZH}$ & 435 & 10.6 & 982 & clay loam & integrated & 41 & min-org & 0 \\
\hline conv & $\mathrm{ZH}$ & 429 & 10.6 & 982 & clay loam & none & 23 & min-org & $0<>0.5$ \\
\hline conv & $\mathrm{ZH}$ & 576 & 10.4 & 1322 & clay loam & none & 31 & min-org & $>1$ \\
\hline conv & $\mathrm{ZH}$ & 390 & 10.0 & 1007 & clay loam & none & 73 & min-org & $>1$ \\
\hline conv & $\mathrm{ZH}$ & 442 & 10.3 & 1181 & light clay & none & 62 & min-org & $0.5<>1$ \\
\hline $\mathrm{nt}$ & GE & 441 & 11.4 & 793 & clay loam & integrated & 57 & min-org & $0<>0.5$ \\
\hline nt & GE & 403 & 11.7 & 680 & silty clay & integrated & 48 & min-org & 0 \\
\hline nt & GE & 361 & 11.7 & 680 & silty clay loam & none & 107 & min-org & 0 \\
\hline nt & GE & 356 & 11.7 & 680 & loam & none & 76 & min-org & 0 \\
\hline nt & GE & 427 & 11.3 & 786 & clay loam & none & 25 & $\min$ & $0<>0.5$ \\
\hline nt & VD & 429 & 11.3 & 1109 & clay loam & integrated & 66 & $\min$ & $0<>0.5$ \\
\hline nt & VD & 686 & 9.7 & 1013 & light clay & integrated & 144 & min-org & $0.5<>1$ \\
\hline nt & VD & 486 & 10.9 & 839 & loam & integrated & 17 & min-org & $0<>0.5$ \\
\hline nt & VD & 590 & 10.3 & 792 & loam & integrated & 68 & $\min$ & 0 \\
\hline nt & VD & 584 & 10.4 & 778 & light clay & integrated & 31 & min-org & 0 \\
\hline nt & $A G$ & 383 & 10.2 & 934 & loam & integrated & 29 & min-org & $0.5<>1$ \\
\hline nt & LU & 504 & 9.3 & 1080 & clay loam & integrated & 13 & min-org & $0<>0.5$ \\
\hline nt & LU & 506 & 9.3 & 1080 & clay loam & none & 30 & min-org & $0<>0.5$ \\
\hline nt & $\mathrm{ZH}$ & 408 & 10.4 & 967 & clay loam & none & 26 & min-org & $0<>0.5$ \\
\hline nt & $\mathrm{ZH}$ & 518 & 10.4 & 1322 & clay loam & integrated & 35 & min-org & $0.5<>1$ \\
\hline nt & $\mathrm{ZH}$ & 457 & 10.6 & 982 & clay loam & integrated & 13 & min-org & 0 \\
\hline nt & $\mathrm{ZH}$ & 429 & 10.6 & 982 & light clay & none & 31 & $\min$ & 0 \\
\hline nt & $\mathrm{ZH}$ & 576 & 10.4 & 1322 & light clay & integrated & 29 & min-org & $>1$ \\
\hline $\mathrm{nt}$ & $\mathrm{ZH}$ & 390 & 10.0 & 1007 & clay loam & none & 34 & min-org & $0<>0.5$ \\
\hline nt & $\mathrm{ZH}$ & 442 & 10.3 & 1181 & light clay & integrated & 12 & min-org & 0 \\
\hline org & GE & 437 & 11.3 & 879 & clay loam & organic & 87 & org & $0<>0.5$ \\
\hline org & GE & 437 & 11.3 & 879 & light clay & organic & 71 & org & 0 \\
\hline org & GE & 435 & 11.4 & 793 & clay loam & organic & 20 & org & 0 \\
\hline org & VD & 733 & 10.1 & 805 & loam & organic & 28 & org & $0.5<>1$ \\
\hline org & VD & 613 & 10.3 & 792 & clay loam & organic & 46 & org & $0<>0.5$ \\
\hline org & VD & 443 & 10.9 & 839 & clay loam & organic & 27 & org & 0 \\
\hline org & VD & 456 & 11.6 & 1063 & clay loam & organic & 47 & org & 0 \\
\hline org & VD & 618 & 10.3 & 792 & clay loam & organic & 76 & org & 0 \\
\hline org & VD & 442 & 10.4 & 778 & clay loam & organic & 46 & org & $0.5<>1$ \\
\hline org & $\mathrm{FR}$ & 449 & 10.9 & 839 & loam & organic & 40 & org & $0.5<>1$ \\
\hline org & $A G$ & 425 & 10.2 & 934 & clay loam & organic & 20 & org & $>1$ \\
\hline org & LU & 554 & 9.3 & 1080 & loam & organic & 119 & org & $0.5<>1$ \\
\hline org & LU & 506 & 9.3 & 1080 & clay loam & organic & 15 & org & $0.5<>1$ \\
\hline org & $\mathrm{ZH}$ & 408 & 10.4 & 967 & clay loam & organic & 36 & org & $>1$ \\
\hline org & $\mathrm{ZH}$ & 518 & 10.4 & 1322 & light clay & organic & 22 & org & $>1$ \\
\hline org & $\mathrm{ZH}$ & 465 & 10.6 & 982 & clay loam & organic & 18 & org & 0 \\
\hline org & $\mathrm{ZH}$ & 429 & 10.6 & 982 & clay loam & organic & 18 & org & $>1$ \\
\hline org & $\mathrm{ZH}$ & 576 & 10.4 & 1322 & light clay & organic & 25 & org & $>1$ \\
\hline org & $\mathrm{ZH}$ & 442 & 10.3 & 1181 & light clay & organic & 29 & org & $0.5<>1$ \\
\hline org & TG & 416 & 10.0 & 1007 & light clay & organic & 21 & org & $>1$ \\
\hline
\end{tabular}


Table S2 Data collected in the questionnaire survey (rows), filled in by the farmers, and used to compute the 32 cropping practice indicators (columns). The crosses indicate which data has been used for which indicator.

General information at farm level

utilised agricultural area [ha]

annual working unit

livestock unit

all main crops present on the farm in 2015-2016

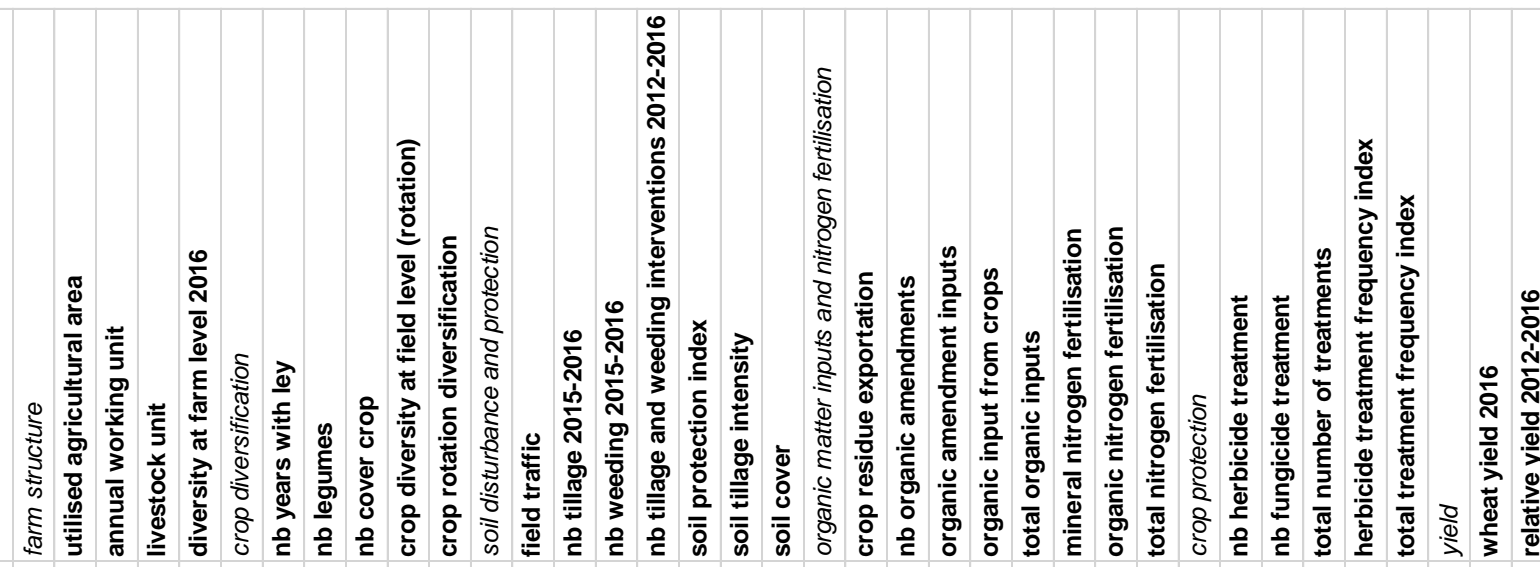

Detailed management practices for the wheat cultivation year (2015-2016)

$\Rightarrow>$ for each intervention:

date

intervention type (tillage, weeding, seeding, treatment, fertilisation)

implement

product (type, quantity)

$\mathrm{X}$

$X$

$X$

Historical data on the 5 year rotation (2012-2016), at field level => for each year:

main crop

estimated yield [t/ha]

organic fertilisation (type, quantity)

cover crop (presence or not, species)

type of soil tillage (no till, reduced, plough)

estimated number of tillage and weeding interventions

management of crop residue (exported or left on the field)

$\mathrm{x} \times$

$\begin{array}{rr}X \\ X \\ x & x\end{array}$

\begin{tabular}{l|l}
$X$ & $X$ \\
$X$ & $X$
\end{tabular}
$\begin{array}{llllllll}X & X & X & X & X & X & X & X\end{array}$

\begin{tabular}{ll|l}
$X X$ & $X$
\end{tabular} 
Table S3 Isohumic coefficients and nitrogen availability of organic amendments used in the computation of the organic amendment inputs (qOrg), total organic inputs (totOrg), nitrogen organic fertilisation (orgN) and total nitrogen fertilisation indicators (totN).

\begin{tabular}{|c|c|c|c|c|}
\hline source of organic matter & $\begin{array}{l}\text { dry organic matter }{ }^{\mathrm{a}} \\
{\left[\mathrm{kg} / \mathrm{t} \text { or }{ }^{*} \mathrm{~kg} / \mathrm{m} 3\right]}\end{array}$ & isohumic coefficient & $\begin{array}{l}\text { total nitrogen }{ }^{\mathrm{a}} \\
{\left[\mathrm{kg} / \mathrm{t} \text { or }{ }^{*} \mathrm{~kg} / \mathrm{m} 3\right]}\end{array}$ & part of available nitrogen ${ }^{b}$ \\
\hline cow slurry & $50^{\star}$ & 0.10 & $4.3^{*}$ & 0.45 \\
\hline cow manure & 150 & 0.50 & 4.9 & 0.15 \\
\hline fattening cow slurry & $65^{*}$ & 0.10 & $4.3^{*}$ & 0.45 \\
\hline fattening cow manure & 155 & 0.35 & 5.4 & 0.20 \\
\hline pig slurry & $33^{*}$ & 0.10 & $4.7^{\star}$ & 0.50 \\
\hline pig manure & 40 & 0.35 & 7.8 & 0.35 \\
\hline poultry manure & 330 & 0.25 & 27.0 & 0.35 \\
\hline horse manure & 270 & 0.40 & 5.6 & 0.10 \\
\hline compost & 214 & 0.25 & 7.0 & 0.05 \\
\hline composted manure & 200 & 0.65 & 4.9 & 0.15 \\
\hline liquid digestate & $50^{*}$ & 0.28 & 4.0 & 0.50 \\
\hline ramial chipped wood (BRF) & 422 & 0.50 & $1.6^{*}$ & 0.00 \\
\hline
\end{tabular}

${ }^{a}$ dry organic matter and total nitrogen are given in $\mathrm{kg} / \mathrm{t}$, except for values marked with *, in $\mathrm{kg} / \mathrm{m} 3$

${ }^{b}$ part of total nitrogen available for the crop the year of application

Most coefficients were extracted from the Swiss principles of agricultural crop fertilisation (Sinaj and Richner, 2017) or extrapolated from similar products, except for digestate isohumic coefficient (CSICM, 2010) and for the ramial chipped wood coefficients (CTACF, 2006)

\section{References}

CSICM, 2010. Directive suisse 2010 de la branche sur la qualité du compost et du digestat. Commission suisse de l'inspectorat du compostage et de la méthanisation, $40 \mathrm{pp}$.

CTACF, 2006. Mise en oeuvre de la technique du Bois Raméal Fragmenté (BRF) en agriculture wallonne. Centre des Technologies Agronomiques Communauté Française, 168 pp.

Sinaj, S., Richner, W., 2017. Principes de fertilisation des cultures agricoles en Suisse (PRIF 2017). Recherche Agronomique Suisse 8(6). 
Table S4 Mean values and standard errors of the 31 indicators for the three cropping systems, and p-values from the overall analysis of variance ('global') and from the Tukey HSD post-hoc pairwise test. 'conv': conventional farming, 'nt': no-till farming, 'org': organic farming.

\begin{tabular}{|c|c|c|c|c|c|c|c|c|c|c|}
\hline \multirow[t]{2}{*}{ Indicator } & \multicolumn{2}{|l|}{ conv } & & \multicolumn{2}{|l|}{ org } & \multicolumn{4}{|c|}{ p-values } \\
\hline & mean & se & mean & se & mean & se & anova & nt-conv & org-con & norg-nt \\
\hline \multicolumn{11}{|l|}{ Farm structure } \\
\hline utilised agricultural area [ha] & 62 & 10 & 44 & 8 & 41 & 6 & 0.142 & 0.278 & 0.149 & 0.932 \\
\hline annual working unit & 2.6 & 0.5 & 1.9 & 0.4 & 2.0 & 0.2 & 0.464 & 0.466 & 0.617 & 0.966 \\
\hline livestock unit & 0.70 & 0.17 & 0.27 & 0.09 & 0.73 & 0.14 & 0.035 & 0.077 & 0.991 & 0.053 \\
\hline diversity at farm level 2016 & 6.58 & 0.34 & 6.25 & 0.45 & 7.15 & 0.55 & 0.376 & 0.870 & 0.659 & 0.350 \\
\hline \multicolumn{11}{|l|}{ Crop diversification } \\
\hline nb years with ley & 0.26 & 0.18 & 0.30 & 0.18 & 1.25 & 0.22 & 0.001 & 0.990 & 0.002 & 0.003 \\
\hline nb legume crops & 1.16 & 0.22 & 2.05 & 0.29 & 2.35 & 0.22 & 0.004 & 0.038 & 0.004 & 0.667 \\
\hline nb cover crops & 1.16 & 0.22 & 1.90 & 0.32 & 0.85 & 0.20 & 0.013 & 0.101 & 0.663 & 0.011 \\
\hline crop diversity at field level (rotation) & 4.63 & 0.24 & 5.00 & 0.23 & 4.30 & 0.18 & 0.082 & 0.466 & 0.538 & 0.066 \\
\hline crop rotation diversification & 6.17 & 0.27 & 7.18 & 0.55 & 7.00 & 0.41 & 0.218 & 0.228 & 0.364 & 0.952 \\
\hline \multicolumn{11}{|l|}{ Soil disturbance and protection } \\
\hline field traffic & 10.5 & 0.5 & 9.1 & 0.3 & 9.8 & 0.5 & 0.081 & 0.065 & 0.503 & 0.468 \\
\hline nb tillage 2015-2016 & 1.32 & 0.15 & 0.40 & 0.13 & 2.55 & 0.27 & 0.000 & 0.005 & 0.000 & 0.000 \\
\hline nb weeding 2015-2016 & 0.00 & 0.00 & 0.00 & 0.00 & 2.35 & 0.26 & 0.000 & 1.000 & 0.000 & 0.000 \\
\hline $\mathrm{nb}$ tillage and weeding interventions $2012-2016$ & 2.32 & 0.20 & 0.18 & 0.08 & 4.06 & 0.46 & 0.000 & 0.000 & 0.000 & 0.000 \\
\hline soil protection index & 1.63 & 0.15 & 4.72 & 0.10 & 1.82 & 0.23 & 0.000 & 0.000 & 0.713 & 0.000 \\
\hline soil tillage intensity & 94 & 7 & 24 & 3 & 139 & 6 & 0.000 & 0.000 & 0.000 & 0.000 \\
\hline soil cover & 0.28 & 0.05 & 0.56 & 0.05 & 0.18 & 0.03 & 0.000 & 0.000 & 0.244 & 0.000 \\
\hline \multicolumn{11}{|l|}{ Organic matter inputs and nitrogen fertilisation } \\
\hline crop residue exportation & 2.37 & 0.32 & 1.60 & 0.37 & 2.75 & 0.38 & 0.072 & 0.288 & 0.731 & 0.063 \\
\hline $\mathrm{nb}$ organic amendments & 5.05 & 0.05 & 5.05 & 0.05 & 5.40 & 0.18 & 0.055 & 1.000 & 0.096 & 0.087 \\
\hline organic amendment inputs [kg OMha] & 465 & 105 & 435 & 130 & 470 & 150 & 0.979 & 0.986 & 1.000 & 0.980 \\
\hline organic input from crops [kg OMha] & 683 & 37 & 726 & 32 & 708 & 41 & 0.712 & 0.690 & 0.880 & 0.936 \\
\hline total organic inputs [kg OMha] & 1148 & 113 & 1161 & 134 & 1178 & 140 & 0.986 & 0.997 & 0.985 & 0.995 \\
\hline mineral nitrogen fertilisation [kg N/ha] & 141 & 7 & 127 & 8 & 0 & 0 & 0.000 & 0.217 & 0.000 & 0.000 \\
\hline organic nitrogen fertilisation [kg N/ha] & 19 & 7 & 20 & 6 & 61 & 5 & 0.000 & 0.978 & 0.000 & 0.000 \\
\hline total nitrogen fertilisation [kg N/ha] & 160 & 6 & 147 & 4 & 61 & 5 & 0.000 & 0.201 & 0.000 & 0.000 \\
\hline \multicolumn{11}{|l|}{ Crop protection } \\
\hline $\mathrm{nb}$ herbicide treatment & 1.11 & 0.11 & 2.30 & 0.24 & 0.00 & 0.00 & 0.000 & 0.000 & 0.000 & 0.000 \\
\hline $\mathrm{nb}$ fungicide treatment & 1.16 & 0.33 & 0.30 & 0.18 & 0.00 & 0.00 & 0.001 & 0.016 & 0.001 & 0.569 \\
\hline total number of treatments & 3.11 & 0.54 & 2.70 & 0.26 & 0.00 & 0.00 & 0.000 & 0.678 & 0.000 & 0.000 \\
\hline herbicide treatment frequency index & 1.18 & 0.20 & 2.32 & 0.23 & 0.00 & 0.00 & 0.000 & 0.000 & 0.000 & 0.000 \\
\hline total treatment frequency index & 2.77 & 0.43 & 2.71 & 0.24 & 0.00 & 0.00 & 0.000 & 0.988 & 0.000 & 0.000 \\
\hline \multicolumn{11}{|l|}{ Yield } \\
\hline wheat yield 2016 [t/ha] & 5.6 & 0.4 & 4.9 & 0.3 & 3.4 & 0.2 & 0.000 & 0.174 & 0.000 & 0.001 \\
\hline relative yield 2012-2016 & 1.05 & 0.03 & 0.93 & 0.03 & 0.70 & 0.03 & 0.000 & 0.020 & 0.000 & 0.000 \\
\hline
\end{tabular}




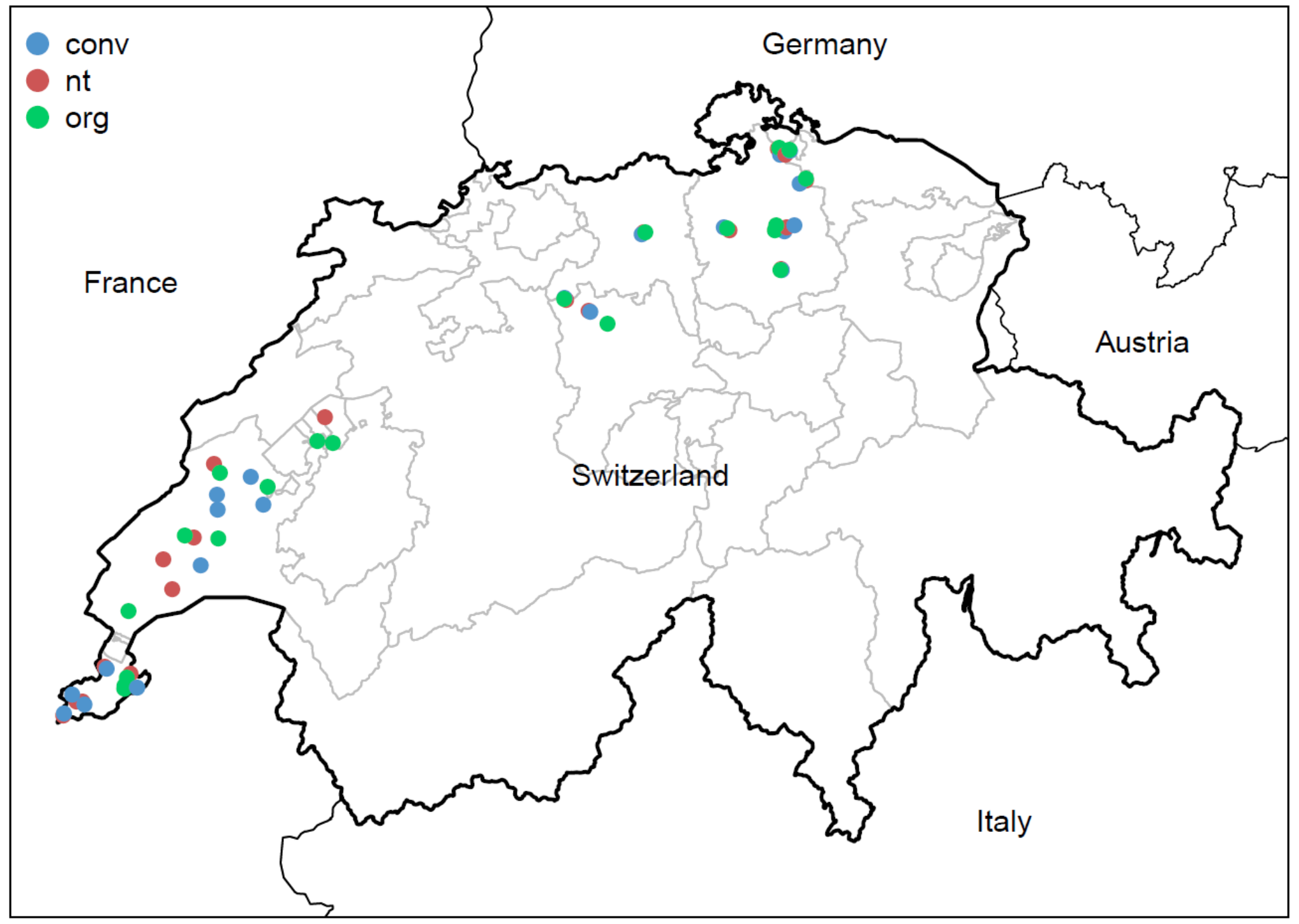

Figure S1 Map of Switzerland showing the geographic position of the 60 fields. Blue points correspond to conventional systems, red points to no till systems and green points to organic systems. 


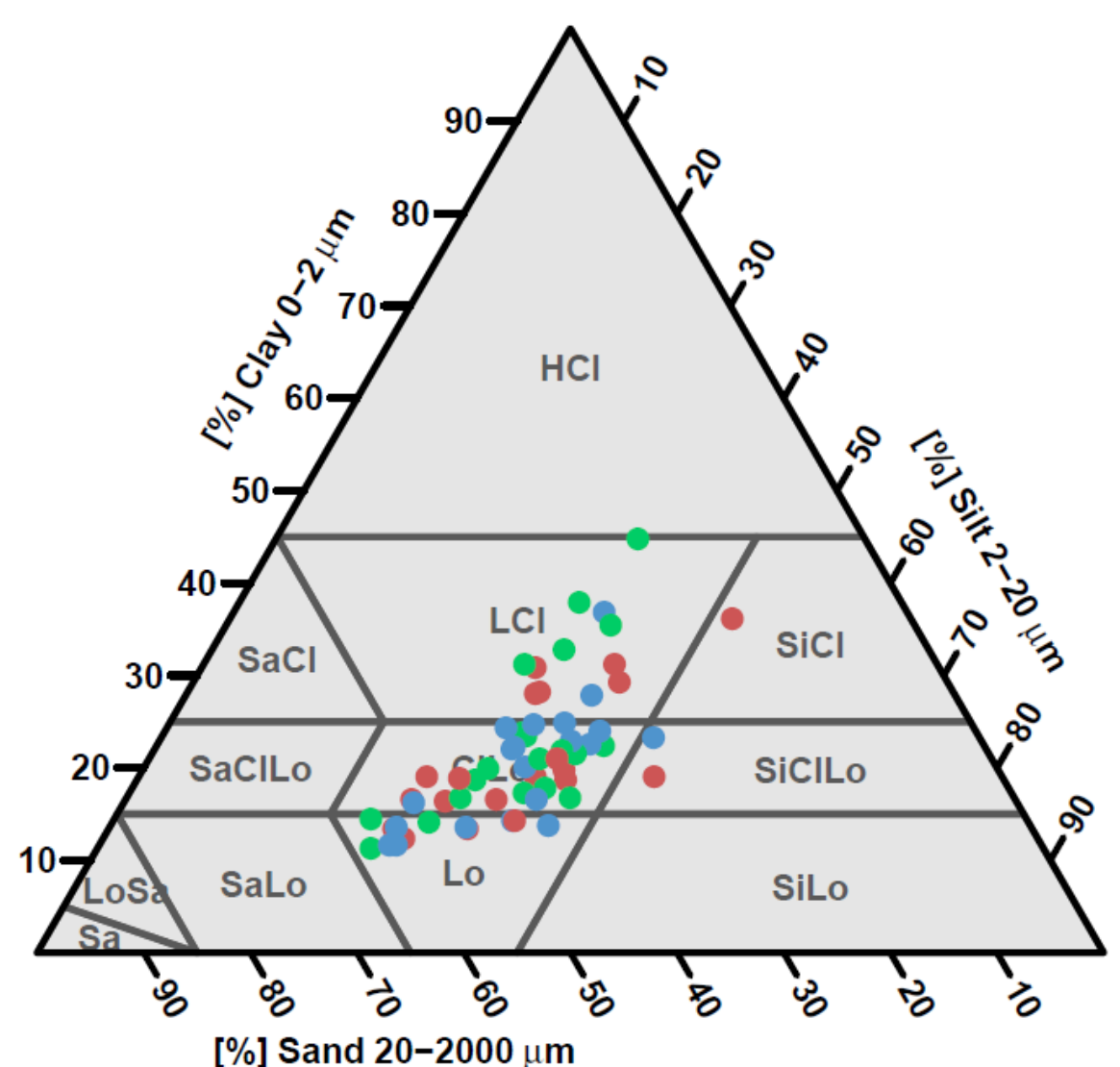

Figure S2 Texture triangle (ISSS system) showing the texture $(0-20 \mathrm{~cm})$ of the 60 fields. Blue points correspond to conventional systems, red points to no till systems and green points to organic systems. 

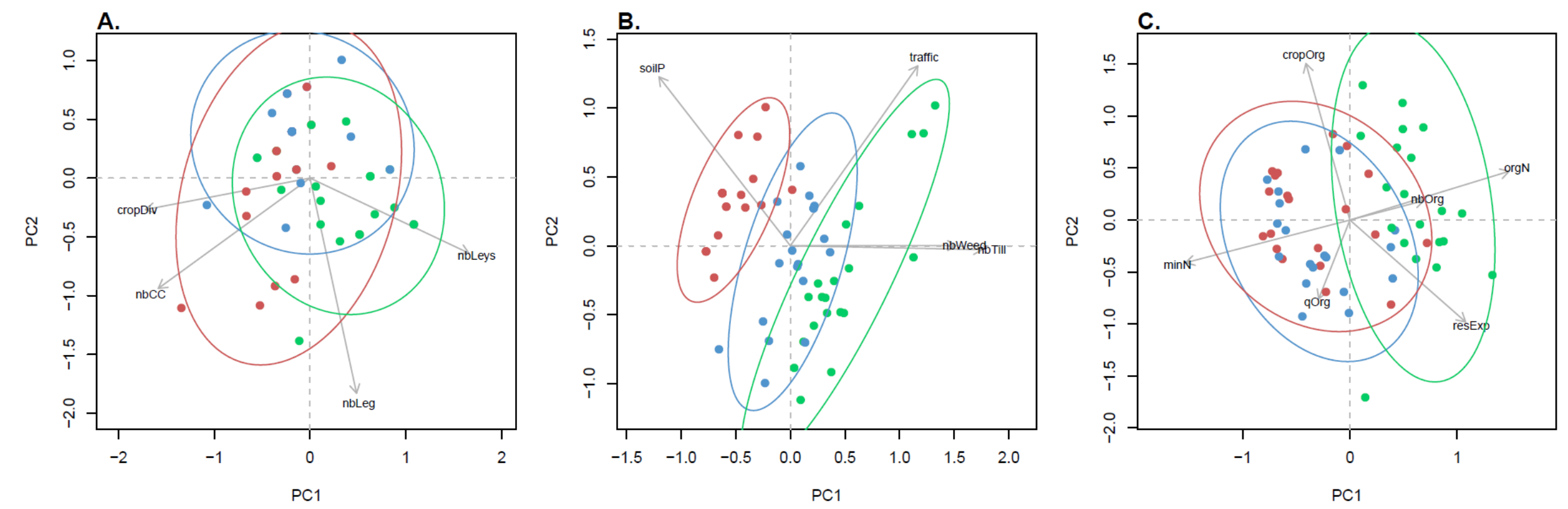

Figure S3 Principal component analyses (field projection, scaling 2) used for the computation of the composite indexes for A. Crop diversification, B. Soil disturbance and protection, and C. Organic matter inputs and nitrogen fertilisation. Blue points correspond to conventional systems, red points to no-till systems and green points to organic systems. Correspondence between abbreviations and indicator names are given in Table 1 . 


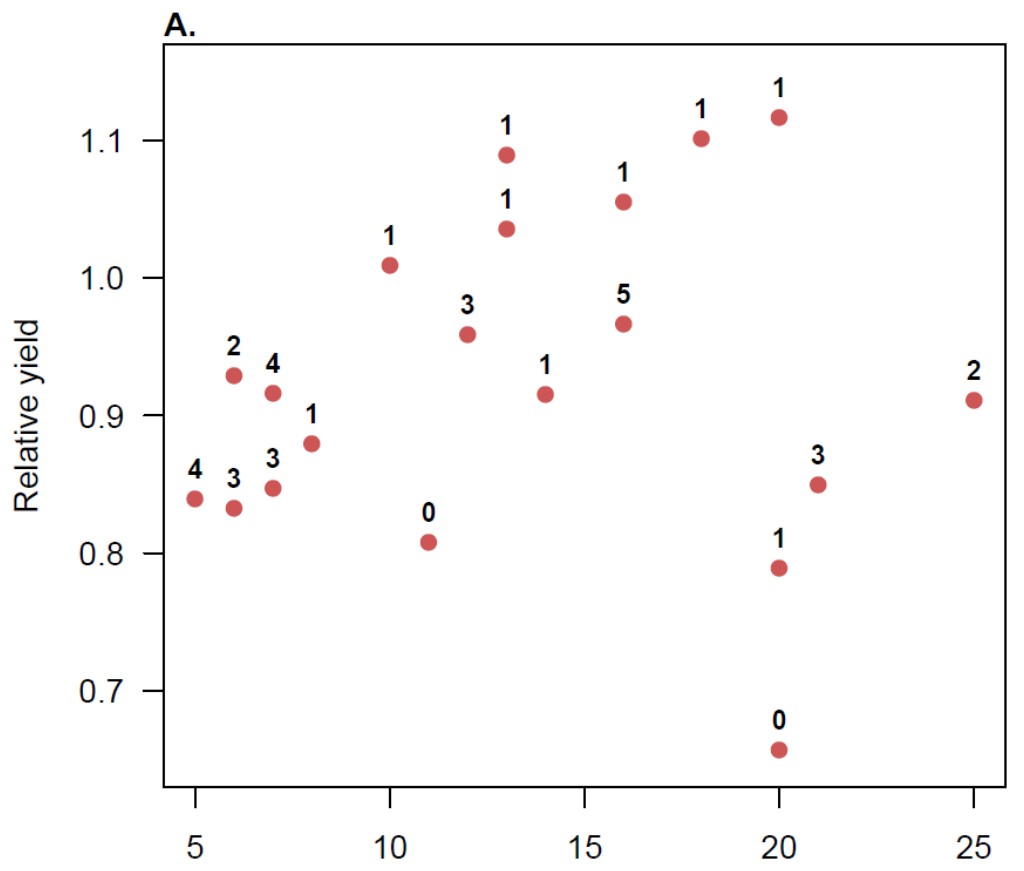

Number of years of no till practice

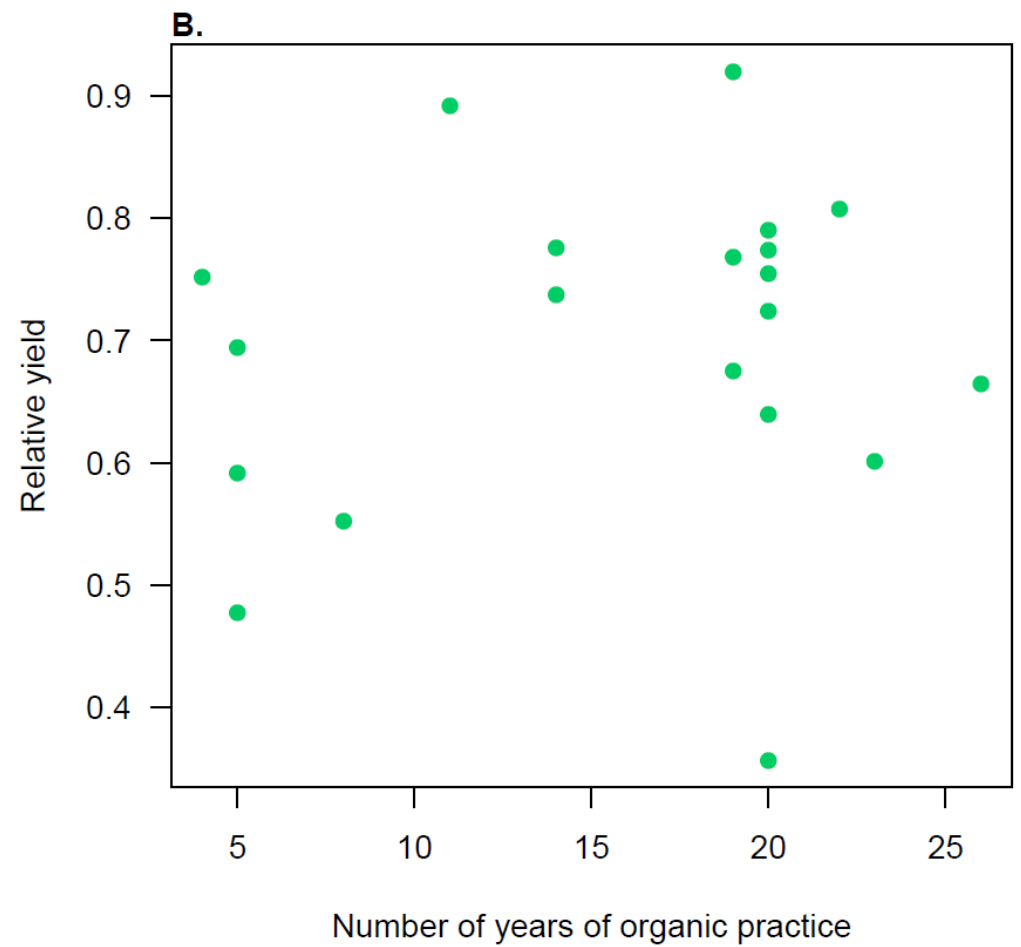

Figure S5 Relative yield indicator as a function of time since the beginning of A. no till practice and B. organic practice. In panel A, the numbers above the points indicate the number of cover crops cultivated the past 5 years (number of cover crop 'nbCC' indicator). 


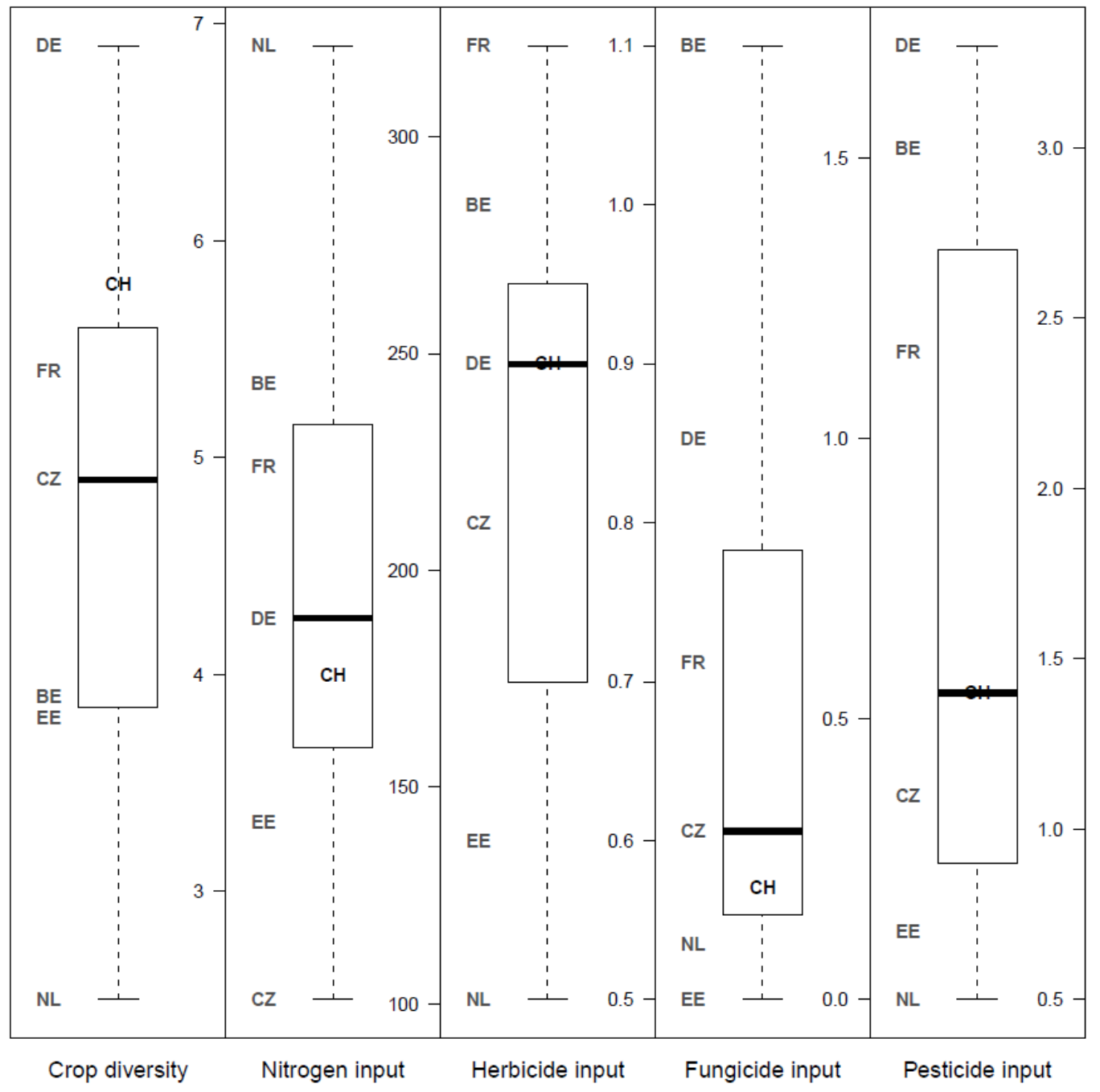

Figure S6 Comparison of Switzerland with six other European countries in terms of crop diversity, nitrogen fertilisation and pesticide inputs. On each box, ' $\mathrm{CH}$ ' shows the position of Switzerland. On the left of each box, the two letter code of each other country is indicated, BE: Belgium, CZ: Czech Republic, EE: Estonia, FR: France, DE:

Germany, NL: Netherlands. The data come from Herzog et al. (2006).

\section{Reference}

Herzog, F., Steiner, B., Bailey, D., Baudry, J., Billeter, R., Bukacek, R., De Blust, G., De Cock, R., Dirksen, J., Dormann, C.F., De Filippi, R., Frossard, E., Liira, J., Schmidt, T., Stöckli, R., Thenail, C., van Wingerden W., Bugter, R. 2006. Assessing the intensity of temperate European agriculture at the landscape scale. Europ. J. Agron. 165-181. 